\title{
Convergent Inputs from Thalamic Motor Nuclei and Frontal Cortical Areas to the Dorsal Striatum in the Primate
}

\author{
Nikolaus R. McFarland and Suzanne N. Haber \\ Department of Neurobiology and Anatomy, University of Rochester School of Medicine and Dentistry, Rochester, \\ New York 14642
}

Current models of basal ganglia circuitry primarily associate the ventral thalamic nuclei with relaying basal ganglia output to the frontal cortex. However, some studies have demonstrated projections from the ventral anterior (VA) and ventral lateral (VL) thalamic nuclei to the striatum, suggesting that these nuclei directly modulate the striatum. VA/VL nuclei have specific connections with primary, supplementary, premotor, and cingulate motor cortices indicating their involvement in motor function. These areas mediate different aspects of motor control such as movement execution, motor learning, and sensorimotor integration. Increasing evidence indicates that functionally related motor areas have convergent projections to the dorsal striatum, suggesting that integration of different aspects of motor control occur at the level of the striatum. This study examines the organization of VA/VL thalamic inputs to the dorsal "motor" striatum to determine how this afferent projection is organized

The thalamus provides the second largest source of excitatory input to the striatum. The role of the thalamostriatal projection, however, remains unclear and has consequently been relatively ignored in models of basal ganglia function. Although the midline and intralaminar thalamic nuclei are most often associated with the thalamostriatal projection (Jones and Leavitt, 1974; Fénelon et al., 1991; Giménez-Amaya et al., 1995), some studies have also shown projections from the ventral anterior (VA) and ventral lateral (VL) thalamic nuclei (Smith and Parent, 1986; Nakano et al., 1990; Druga et al., 1991). Despite this, current models of basal ganglia circuitry only associate the VA/VL nuclei with relaying basal ganglia output from the globus pallidus and substantia nigra, pars reticulata to the frontal cortex (Alexander et al., 1990; DeLong, 1990; Wichmann and DeLong, 1996). Direct thalamostriatal projections from VA/VL nuclei indicate that these nuclei play a primary role in modulating the striatum. Although the intralaminar nuclei are less well defined with respect to their circuitry and function, the fact that the ventral tier thalamic nuclei have specific connections with motor, premotor, and cingulate motor cortices indicates their involvement in motor function (Schell and Strick, 1984; Wiesendanger and Wiesendanger, 1985;

\footnotetext{
Received Jan. 14, 2000; revised March 7, 2000; accepted March 9, 2000.

This work was supported by National Institutes of Health Grants MH11661 (N.R.M.) and NS22511 (S.N.H.) and a grant from the Lucielle Markey Charitable Trust. We thank April Whitbeck and Evelyn Galban for their technical help.

Correspondence should be addressed to Dr. Suzanne N. Haber, Department of Neurobiology and Anatomy, University of Rochester School of Medicine and Dentistry, 601 Elmwood Avenue, Box 603, Rochester, New York 14642. E-mail: suzanne_haber@urmc.rochester.edu.

Copyright (C) 2000 Society for Neuroscience $\quad 0270-6474 / 00 / 203798-16 \$ 15.00 / 0$
}

with respect to corticostriatal afferents from motor, premotor, and cingulate motor areas. Motor cortical projections to specific dorsal striatal regions arose from multiple areas, including components from primary motor, premotor, supplementary, and cingulate motor areas. Diverse motor cortical projections to a given dorsal striatal region indicated convergence of functionally related corticostriatal motor pathways. Most dorsal striatal sites received dense thalamic inputs from the $V L$ pars oralis nucleus. Additional thalamostriatal projections arose from VA, VL pars caudalis, and ventral posterior lateral pars oralis nuclei and Olszewski's Area X. Our results provide evidence for convergent striatal projections from interconnected ventral thalamic and cortical motor areas, suggesting that these afferents modulate the same striatal output circuits.

Key words: thalamostriatal; corticostriatal; ventral anterior; ventral lateral; supplementary motor area; cingulate cortex
Vogt et al., 1987; Matelli et al., 1989; Holsapple et al., 1991; Kurata, 1994; Matelli and Luppino, 1996).

Primary, supplementary, premotor, and cingulate motor areas mediate different aspects of motor control (Alexander and Crutcher, 1990; Shima et al., 1991; Matsuzaka et al., 1992; Dum and Strick, 1993; Kurata, 1993; Rizzolatti et al., 1996; Graziano et al., 1997). Primary motor, the caudal premotor, supplementary (SMA-proper), and cingulate motor (CMAc) areas are predominately involved in movement execution, whereas the rostral premotor, presupplementary (Pre-SMA), and cingulate motor (CMAr) areas are involved in motor learning and sensorimotor integration. Medial (i.e., SMA and cingulate) and lateral premotor areas also play important roles in internally versus externally guided movements, respectively (Kurata and Wise, 1988; Mushiake et al., 1991; Kimura et al., 1992; Kurata and Hoffman, 1994).

These cortical regions all project to the dorsal "motor" striatum, including the dorsal, postcommissural putamen and the dorsolateral head of the caudate (Haber et al., 1994; Parent and Hazrati, 1995). Prevailing theory suggests that the striatum simultaneously processes multiple motor cortical projections, carrying different aspects of motor control, in parallel. However, increasing evidence indicates that certain motor areas, such as the primary and supplementary motor cortices, have convergent projections to the dorsal striatum (Inase et al., 1996; Takada et al., 1998a,b). Execution of complex behaviors requires sequencing, coordination, and, ultimately, the execution of movements. Convergent corticostriatal projections from functionally related motor areas [e.g., primary motor cortex (M1) and SMA] suggest that such integration of motor functions occurs at the level of the striatum. Because ventral thalamic nuclei are intimately related to 

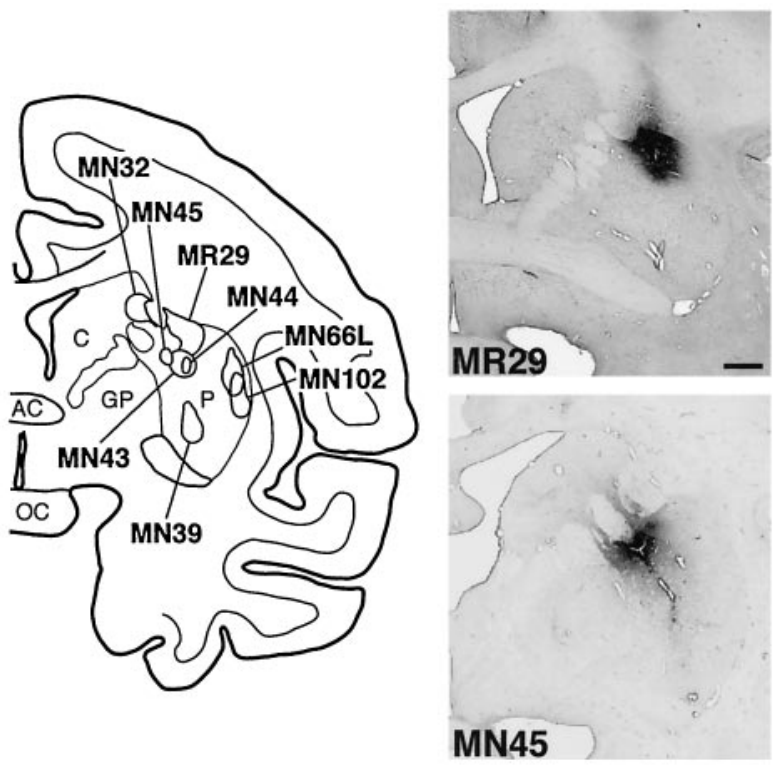

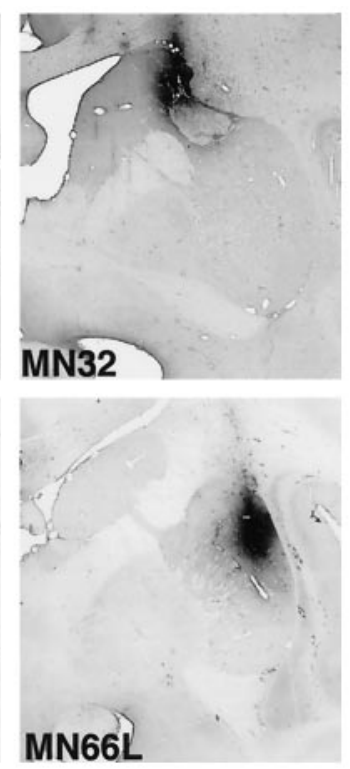

Figure 1. Coronal section illustrating the relative distribution of dorsal striatal injection sites and photomicrographs of representative tracer injections. Scale bar, $2 \mathrm{~mm}$. $A C$, Anterior commissure; $C$, caudate nucleus; $G P$, globus pallidus; $O C$, optic chiasm; $P$, putamen. specific frontal motor areas, ventral thalamic projections to the dorsal striatum may also play a critical role in integrating corticostriatal motor circuits. Thus, the goal of this study was to examine the organizational relationship of ventral thalamostriatal projections to motor cortical afferents within particular subregions of the dorsal "motor" striatum.

To examine the organization of multiple motor cortical and ventral thalamic afferents, we placed discrete injections of retrograde tracers into different regions of the dorsal striatum. On the basis of the distribution and relative density of motor cortical projections to specific dorsal striatal sites, we characterized functional subregions within the dorsal motor striatum. Then we compared the organization of ventral thalamic projections with that of motor cortical afferents to the same dorsal striatal site. In particular, we examined the hypothesis that interconnected frontal cortical and ventral thalamic areas project to the same dorsal striatal regions.

\section{MATERIALS AND METHODS}

Surgery and tissue preparation. Eight adult, macaque monkeys (Macaca mulatta and M. nemestrina) were used for these retrograde tracing experiments. Before surgery, monkeys were tranquilized by intramuscular injection of ketamine $(10 \mathrm{mg} / \mathrm{kg})$, and a surgical plane of anesthesia was maintained by intravenous injection of pentobarbital (initial dose 20 $\mathrm{mg} / \mathrm{kg}$, i.v., and maintained as needed). Temperature, heart rate, and respiration were monitored throughout the surgery. Monkeys were placed in a Kopf stereotaxic, a midline scalp incision was made, and the muscle and fascia were displaced laterally to expose the skull. A craniotomy $\left(\sim 2-3 \mathrm{~cm}^{2}\right)$ was made over the region of interest, and small dural incisions were made only at recording or injection sites. Serial electrode penetrations were performed to identify patterns of neuronal activity that indicate the boundaries of different basal ganglia structures and to locate the desired injection sites (Haber et al., 1993). Accurate placement of tracer injections was achieved by careful alignment of the injection cannulae with the electrode.

The retrograde tracers, wheat germ agglutinin conjugated to horseradish peroxidase (WGA-HRP; $40-50 \mathrm{nl}, 4 \%$ in distilled water; Sigma, St. Louis, MO), and Lucifer Yellow conjugated to dextran amine (LY; $40-50 \mathrm{nl}, 10 \%$ in $0.1 \mathrm{M}$ phosphate buffer (PB), pH 7.4; Molecular Probes, Eugene, OR), were pressure-injected over $10 \mathrm{~min}$ into several different areas of the dorsolateral caudate and putamen using a $0.5 \mu$ l Hamilton syringe (Fig. 1). After each injection, the syringe remained in situ for 20-30 min. Ten to twelve days after surgery, the animals were again deeply anesthetized and perfused with saline followed by a $4 \%$ paraformaldehyde/1.5\% sucrose solution in $0.1 \mathrm{M}$ phosphate buffer, $\mathrm{pH}$ 7.4.
Brains were post-fixed overnight and cryoprotected in increasing gradients of sucrose $(10,20$, and $30 \%)$. Serial sections of $50 \mu \mathrm{m}$ were cut on a freezing microtome into $0.1 \mathrm{M}$ phosphate buffer or cryoprotectant solution.

Immunohistochemistry. Immunocytochemistry was performed on freefloating sections to visualize tracers. Before incubation in primary antisera, tissue was treated with $10 \%$ methanol and $3 \%$ hydrogen peroxide in $0.1 \mathrm{M} P \mathrm{~PB}$ to inhibit endogenous peroxidase activity and rinsed $1-2 \mathrm{hr}$ in PB. Sections were then preincubated in $10 \%$ normal goat serum (NGS) and $0.3 \%$ Triton X-100 (TX; Sigma) in PB for $30 \mathrm{~min}$. Tissue was placed in the primary antisera, either anti-LY (Molecular Probes, Eugene, OR) diluted 1:2000 or anti-WGA (Sigma) diluted 1:2000 in 10\% NGS and $0.3 \% \mathrm{TX}$ in $\mathrm{PB}$, for $4 \mathrm{~d}$ at $4^{\circ} \mathrm{C}$. For visualization of LY and WGA immunoreactivity, the avidin-biotin reaction (rabbit Vectastain ABC kit, Vector Laboratories, Burlingame, CA) was used in conjunction with diaminobenzidine and nickel-intensification procedures. Tissue was thoroughly rinsed in $\mathrm{PB}$ with $0.3 \% \mathrm{TX}$ before incubation in biotinylated goat anti-rabbit IgG, diluted 1:200 in 10\% NGS and $0.3 \%$ TX in PB at room temperature for $45 \mathrm{~min}$. After extensive rinsing, the tissue was incubated in the avidin-biotin complex solution diluted 1:100 in 10\% NGS and $0.3 \% \mathrm{TX}$ in $\mathrm{PB}$ at room temperature for $1 \mathrm{hr}$. After extensive rinsing, immunoreactivity was visualized using standard diaminobenzidine procedures. Staining was intensified by incubating the tissue for 5-15 $\mathrm{min}$ in a solution of $0.05 \% 3,3^{\prime}$-diaminobenzidine tetrahydrochloride, $0.025 \%$ cobalt chloride, $0.02 \%$ nickel ammonium sulfate, and $0.01 \% \mathrm{H}_{2} \mathrm{O}_{2}$ to yield a black reaction product. Sections were mounted onto gel-coated slides. For most cases, a set of sections $1.2 \mathrm{~mm}$ apart were subsequently counterstained with cresyl violet.

Charting of labeled cells. Retrogradely labeled cells in the thalamus and cortex were charted using a light microscope fitted with a drawing tube. With the aid of a drawing tablet, charts were traced into a Power Macintosh computer to create composite images. Because different species of Macaque monkeys were used in these experiments, retrograde tracer findings were compared qualitatively and quantitatively between species. We found no significant differences in retrograde labeling between rhesus and pig-tail macaques.

Using counterstained or adjacent Nissl-stained coronal sections, we determined the boundaries of cytoarchitectonic areas within the thalamus and the cortex for each animal. In charting labeled corticostriatal neurons, both individual charts of coronal sections and summaries of corticostriatal labeling were made. Summary charts were composed of a combination of a conventional surface view of the dorsal and lateral frontal convexity and an unfolded reconstruction of the cingulate sulcus continuous with medial wall structures (Fig. 2). The method of reconstruction and display of the medial wall was adapted from Matelli et al. (1985, 1991) and Dum and Strick (1991). The distribution of labeled cortical neurons in sections $\sim 0.4 \mathrm{~mm}$ apart was examined. Because most labeled corticostriatal cells resided within layer $\mathrm{V}$, a virtual line could be drawn at the border between layers III and V (in agranular cortex), and 


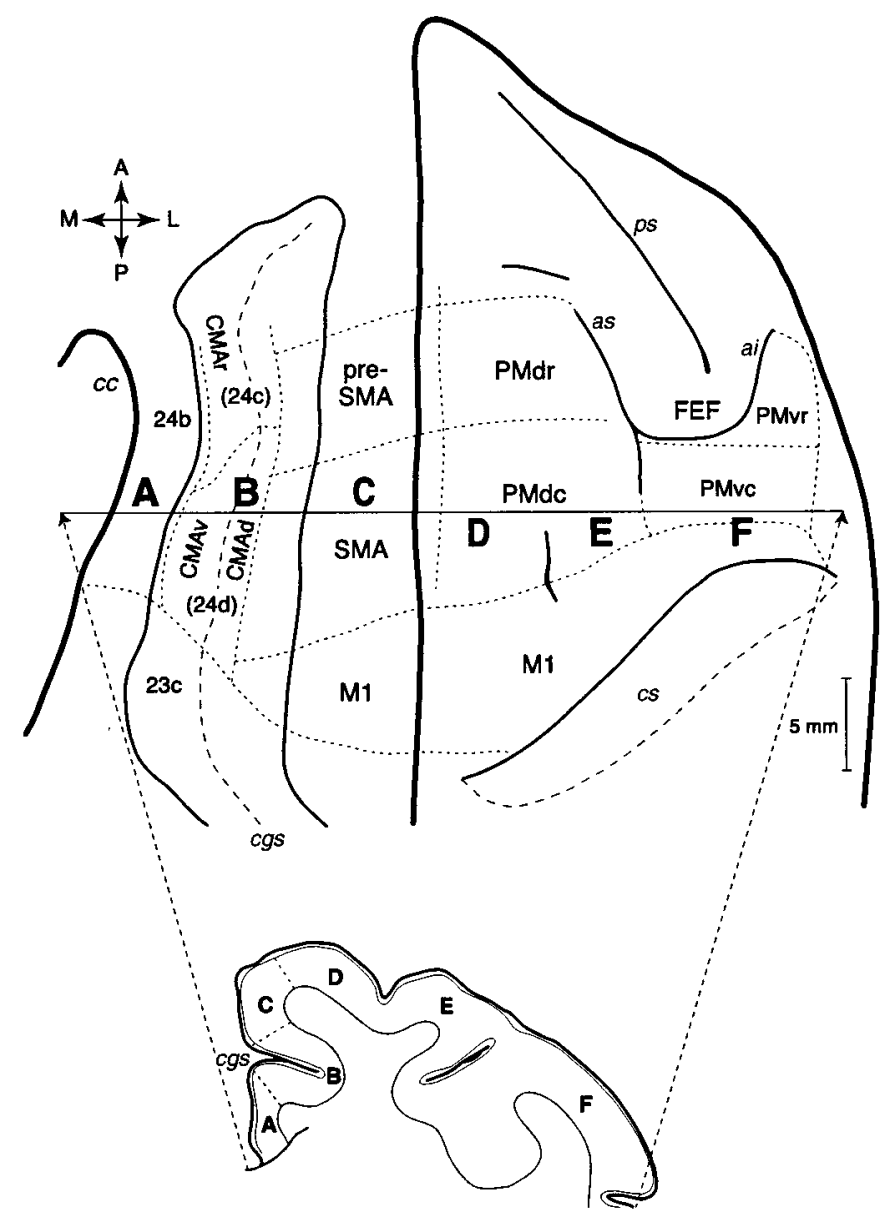

Figure 2. Schematic diagram of motor-related frontal cortical areas used for plotting the distribution of corticostriatal cells [modified figure drawn from Luppino et al. (1993), with permission]. Top schematic illustrates a top-down view of a cerebral hemisphere and its medial surface rotated upward and unfolded to reveal the cingulate sulcus $(\mathrm{cgs})$. Boundaries for cortical motor areas are indicated by fine dotted lines. Sulci are indicated by solid lines [note the fundi of the cingulate and central sulci (cs) are marked with coarse dotted lines]. The coronal slice, below, diagrams the cortical surfaces illustrated in the horizontal line above $(A-F)$. M1, Primary motor cortex; $S M A$, supplementary motor area; $P M d c$, dorsalcaudal premotor cortex; $P M d r$, dorsal-rostral premotor cortex; $P M v c$, ventral-caudal premotor cortex; $P M v r$, ventral-rostral premotor cortex; $F E F$, frontal eye fields; $C M A r$, rostral cingulate motor area; $C M A d$, dorsal CMA; $C M A v$, ventral CMA; $p s$, principal sulcus; as/ai, superior/inferior limb of arcuate sulcus; $c c$, corpus callosum.

the relative density (within each case) of labeled cells projected onto this line was plotted. Straightening this line for cells in the cingulate sulcus allowed plotting of the relative cell density on summary charts, creating the unfolded reconstruction. In charts, we used anatomical descriptions by Matelli et al. $(1985,1991)$ to identify motor and premotor areas of the frontal cortex. Generic nomenclatures for these areas are used for ease of discussion (Fig. 2). Recent studies indicate that a portion of the anterior cingulate cortex, adjacent to mesial premotor areas, contains up to three separate cingulate motor areas (Dum and Strick, 1993; Luppino et al., 1994). Anatomical descriptions by Dum and Strick (1993) and Matelli et al. (1991) were used to chart labeled neurons within these cingulate motor areas.

Several different nomenclatures and schemes have been used for delineating the thalamic nuclei in primates (Olszewski, 1952; Hassler, 1959; Percheron, 1977; Jones, 1985; Ilinsky and Kultas-Ilinsky, 1987; Jones and Hendry, 1989). In this study we used the atlas by Olszewski (1952) in conjunction with anatomical descriptions made by Jones (1985) and Parent et al. (1983) to help delineate the borders among the different thalamic nuclei. We used the terminology of Olszewski (1952) to describe ventral thalamic nuclei, because this terminology has been widely used in studies that examine the ventral thalamic nuclei in coronal sections with regard to basal ganglia and cerebellar afferents (Schell and Strick, 1984; Ilinsky et al., 1985; Carpenter, 1989; Hoover and Strick, 1993). Figure 3 shows Nissl-stained sections through the ventral motor nuclei, illustrating the nuclei subdivisions. We used descriptions by Parent et al. (1983) and Fénelon et al. (1991) to identify the central superior lateral thalamic nucleus and the center median-parafascicular complex (central, or CMPf), respectively.

\section{RESULTS}

To examine the distribution of striatal afferents from ventral tier thalamic nuclei and frontal cortical areas, we injected retrograde tracers into discrete regions of the dorsal motor striatum (Fig. 1). Seven injections were placed into different regions of the postcommissural putamen, including the dorsolateral (cases MN66L, MN102), dorsal-central (cases MR29, MN43, MN44, and MN45), and ventral putamen (case MN39). One injection was located in the adjacent dorsolateral caudate nucleus (MN32). All tracer injections were confined to the striatum. Examination of cortical regions traversed by injection canulae showed no significant leakage or evidence of cortico-cortical labeling.

\section{General cortical and thalamic labeling}

Tracer injections into the dorsal striatum labeled corticostriatal cells bilaterally, with fewer and less widely distributed cells in the contralateral cortex. Dorsal striatal injections resulted in dense labeling in primary, supplementary, premotor, and cingulate motor cortices (Table 1). Individual cases revealed a widespread pattern of convergent corticostriatal inputs from several distinct motor areas. The pattern of labeled motor areas differed depending on the size and location of tracer injection within the dorsal striatum. In general, specific dorsal striatal injections yielded patches of corticostriatal labeling, varying in density, in two or more motor/premotor areas, often including components in the dorsolateral convexity (M1 or PM), medial cortex (SMA/PreSMA), and cingulate motor area (see Fig. 10). In some cases labeling within a given motor area was patchy and also varied in density (see Fig. 6B). Retrogradely labeled cells were primarily found in the superficial part of layer $\mathrm{V}$, but also in layer III (agranular cortical areas) and the deep part of layer V. LYpositive cortical cells were either intensely stained, yielding an almost Golgi-like appearance, or lightly stained with punctate brown-black granules filling the cytoplasm (see Fig. 5B). WGApositive neurons contained dark-brown granular deposits in the cytoplasm and some proximal processes.

In the thalamus, retrograde labeling was ipsilateral. Dorsal striatal injections resulted in dense labeling in ventral tier nuclei including the VA nucleus, Area X, the pars caudalis (VLc) and pars oralis (VLo) divisions of VL, and the ventral posterior lateral pars oralis (VPLo) nucleus (Table 2; see Fig. 10). All tracer injections resulted in dense labeling of the VLo with the exception of case MN39, which primarily labeled VA. In general, thalamostriatal labeling in ventral nuclei other than VLo was less dense and varied according to the location of the injection. The caudal intralaminar nuclei were also densely labeled in all cases. Labeled cells in the center median-parafascicular complex were primarily localized to the central third of the complex, or pars media (see Fig. 10, CMe). 

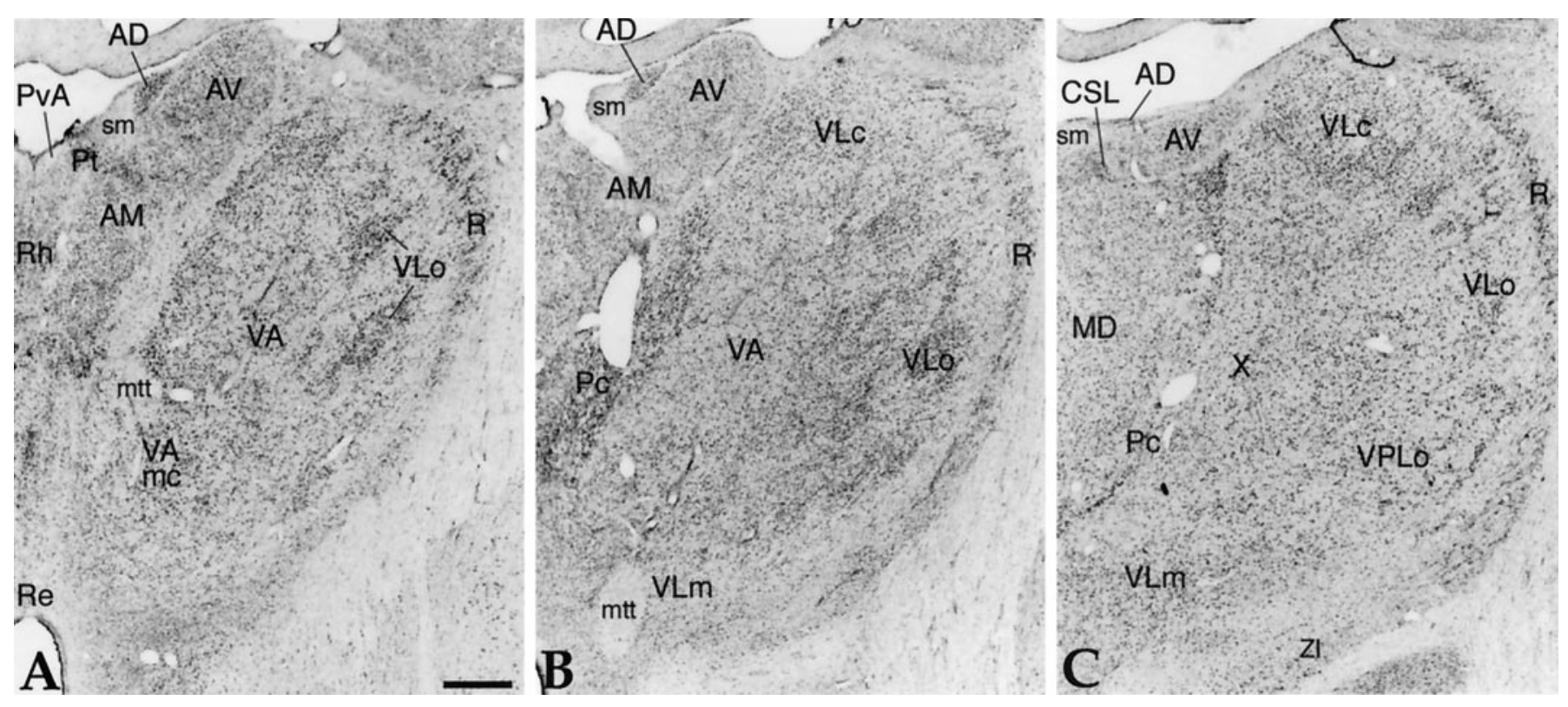

Figure 3. Photomicrographs of Nissl-stained hemisections through the ventral thalamic nuclei. $A-C$ are rostral to caudal sections, $\sim 1.2 \mathrm{~mm}$ apart. Scale bar, $1 \mathrm{~mm}$. $A D$, Anterior dorsal nucleus; $A M$, anterior medial nucleus; $A V$, anterior ventral nucleus; $C S L$, central superior lateral nucleus, $M D$, mediodorsal nucleus; $P c$, paracentral nucleus; $P t$, paratenial nucleus; $P v A$, paraventricular nucleus, anterior; $R$, reticular nucleus; Re, reuniens nucleus; $R h$, rhomboid nucleus; $V A$, ventral anterior pars parvicellular nucleus; $V A m c$, ventral anterior pars magnocelluaris nucleus; $V L c$, ventral lateral pars caudalis nucleus; $V L m$, ventral lateral pars medialis nucleus; $V L O$, ventral lateral pars oralis nucleus; VPI, ventral posterior inferior nucleus; $V P L O$, ventral posterior lateral pars oralis nucleus; $X$, Olszewski's Area X; $Z I$, zona incerta; $m t t$, mammilothalamic tract; sm, striae medialis.

\section{Table 1. Distribution of motor cortical projections to specific dorsal striatal sites}

\begin{tabular}{|c|c|c|c|c|c|c|c|c|}
\hline Cortical area & MN66L & MN102 & MR29 & MN44 & MN43 & MN45 & MN39 & MN32 \\
\hline M1 & ++++ & ++++ & +++ & ++ & + & + & - & - \\
\hline SMA-proper & + & ++ & + & ++++ & ++++ & ++++ & - & - \\
\hline CMAc $(24 d)$ & + & +++ & ++ & + & $+(+)$ & ++ & $(+)$ & - \\
\hline PMdc & - & - & ++++ & ++ & +++ & ++ & - & ++ \\
\hline PMvc & $++(+)$ & + & - & ++ & ++ & + & +++ & - \\
\hline PMvr & - & + & - & + & $(+)$ & +++ & ++++ & - \\
\hline PMdr & - & - & - & - & ++ & + & - & +++ \\
\hline Pre-SMA & - & - & +++ & + & +++ & + & ++ & ++++ \\
\hline CMAr (24c) & - & - & ++ & - & + & + & ++ & $(+)$ \\
\hline
\end{tabular}

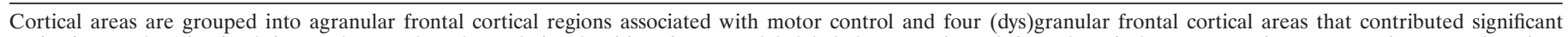

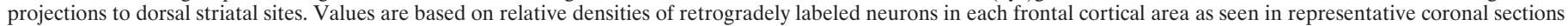

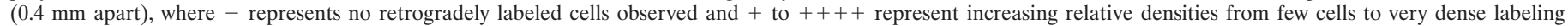

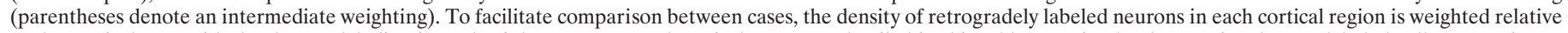

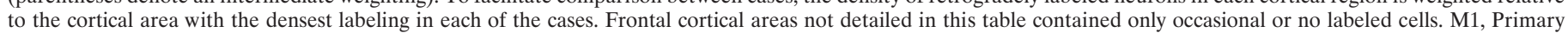

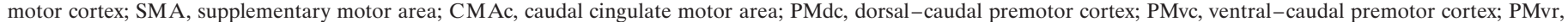
ventral-rostral premotor cortex; PMdr, dorsal-rostral premotor cortex; CMAr, rostral cingulate motor area.

\section{Projections to the dorsolateral putamen}

Cases MN66L and MN102 included injections of WGA-HRP and LY, respectively, located along the dorsolateral border of the postcommissural putamen.

\section{Cortical projections}

Dense cortical labeling was located within distinct regions of the M1 and CMAc areas (Table 1; Figs. 4, 5). In both cases, there were many retrograde cells in the dorsomedial part of M1, extending from the dorsal bank of the cingulate sulcus to the dorsal convexity, corresponding to the leg representation within M1 (Figs. $4 B, 5 D$ ). The distribution of labeled cells in the dorsomedial M1 was widespread and extended rostrally into the SMAproper and caudally to the border of the precentral gyrus. In case
MN102, there was an additional, dense group of WGA-positive cells in M1 located at the dorsal border of and within the central sulcus (Fig. 4B). Caudally, this dense group of labeled cells was continuous with cells on the medial surface. Another dense group of retrograde cells was found in the fundus and ventral bank of the cingulate sulcus, corresponding to the CMAc (Fig. 4A, $C M A c)$. In caudal sections, WGA-positive cells in the cingulate were only in the dorsal bank of the sulcus, less densely distributed and continuous with those in the medial wall of M1. Although the distribution of labeled cells in case MN66L was similar to that in MN102, case MN66L contained an additional, dense group of LY-positive cells in the caudal, ventral premotor cortex (PMvc) (Fig. 5B). Cell labeling in the PMvc was distributed widely in both 


\begin{tabular}{|c|c|c|c|c|c|c|c|c|}
\hline Nucleus & MN66L & MN102 & MR29 & MN44 & MN43 & MN45 & MN39 & MN32 \\
\hline VPLo & +++ & $++(+)$ & $(+)$ & + & - & + & - & - \\
\hline VLo & $+++(+)$ & ++++ & ++++ & +++ & ++++ & +++ & ++ & ++++ \\
\hline VLc & - & + & + & ++ & ++ & ++ & - & +++ \\
\hline Area X & + & + & $(+)$ & +++ & +++ & +++ & - & - \\
\hline VA & + & + & - & + & +++ & ++ & +++ & ++ \\
\hline VAmc & - & + & $(+)$ & + & $(+)$ & - & - & - \\
\hline
\end{tabular}

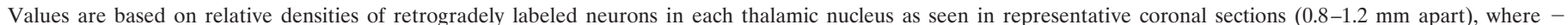

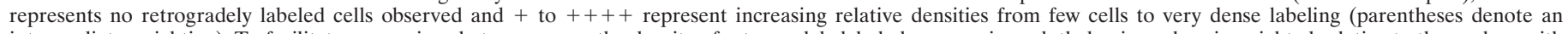

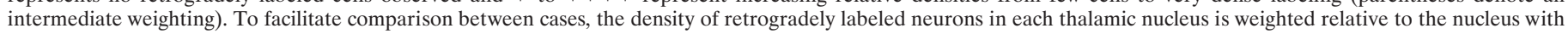

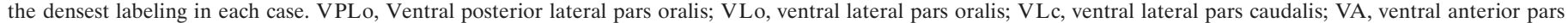
parvicellular; VAmc, ventral anterior pars magnocelluaris.

superficial and deep layers, including cortical layers III, V, and some of VI (Fig. $5 B$ ).

\section{Ventral thalamic projections}

Dense concentrations of retrogradely labeled cells were found in the ventral lateral complex, in particular in the pars oralis divisions of both the VLo and VPLo nuclei (Table 2). Labeling in the caudal half of VLo was especially dense and spanned the dorsoventral extent of the nucleus (Figs. 4C, 5E). There were some scattered labeled neurons in adjacent nuclei medial to VLo, including the VA nucleus and the VLc. Retrograde labeling in VLc was restricted to its rostral, medial portion (Fig. 4D). Within VPLo there were many labeled cells, mainly in its ventromedial half (Figs. $4 D, 5 F, G$ ). Few labeled cells extended medially into Olszewski's Area X.

\section{Projections to the dorsal, central putamen}

Dorsal, central putamen injections included cases MR29 and MN43-45. Case MR29 is an WGA-HRP injection at the dorsal border of the putamen at the level of the decussation of the anterior commissure. Cases MN43-45 are LY injections, located caudal and slightly ventral to MR29.

\section{Cortical projections}

Similar to dorsolateral injections, dorsal, central putamen injections revealed dense frontal cortical labeling in several distinct motor areas (Table 1). In case MR29, dense concentrations of WGA-positive cells were primarily located in the M1; the caudal, dorsal premotor cortex (PMdc), and Pre-SMA (Table 1). Cell labeling in M1 was confined to the rostral, medial wall and extended into the caudal part of SMA (Figs. $6 C$, 10D). In PMdc there were a few distinct patches of labeled cells. The largest and densest cell group was located medial to the dimple in the superior frontal gyrus. Discontinuous patches of moderately dense cell labeling were seen laterally and extended into the arcuate spur (Fig. 6B). Dense cell labeling was also found in the caudal Pre-SMA, primarily in its ventral half, extending into the dorsal bank of the cingulate sulcus (Fig. 6A). In addition, there was a separate, moderately dense group of WGA-positive cells rostrally within the ventral bank of the cingulate sulcus corresponding to the CMAr. Caudally, labeled cells in medial areas were more prominent in the fundus of the cingulate sulcus and the CMAc (Fig. 6B).

In contrast to that in MR29, the distribution of cortical labeling in cases MN43-45 was more widespread and included additional, dense projections from SMA-proper and the ventral premotor cortex (Table 1). In case MN43, LY-positive cells were densest in the rostral half of SMA and extended ventrally into the cingulate sulcus and dorsally into PMdc (Figs. $7 B-D$ ). Labeled cells in PMdc were widely distributed, loosely organized, and extended laterally into the spur of the arcuate sulcus. Labeled cells in the medial and lateral PMdc were continuous with those in the rostral PMd (PMdr). In the ventral PM area (PMvc), there was a separate, moderately dense group LY-positive cells anterior to the central sulcus (Fig. 7C). Dense cell labeling was also present rostrally in Pre-SMA, in particular along the medial wall (Fig. $7 A$ ). LY-positive cells were scattered throughout the cingulate motor areas, but most dense in the rostral half of CMAc, in particular the fundus and ventral bank of the cingulate sulcus (Figs. 7B,C).

\section{Ventral thalamic projections}

As in dorsolateral cases, the densest concentration of retrogradely labeled cells was found in VLo (Table 2). In case MR29 there were dense clusters of WGA-positive cells in the dorsolateral and central parts of VLo (Fig. $6 D-F$ ). Labeled cells in the caudal and ventral part of VLo were more scattered and extended into the lateral half of the ventral lateral, pars medial nucleus (Fig. $6 F, V L m$ ). Dorsally, a few WGA-positive cells were seen in the rostral, central part of VLc. Cases MN43-45 yielded a more widespread distribution of retrograde labeling in ventral tier nuclei than that in case MR29. Although the main concentration of labeled cells was in VLo, there were numerous LY-positive cells throughout the lateral part of VA and Area X (Fig. 7E-G). A few, scattered labeled cells were also seen in the lateral part of magnocellular division of VA (VAmc), VLm, and medial VLc.

\section{Projections to the ventral putamen}

Case MN39 included a WGA-HRP injection into the caudal, ventral part of the dorsolateral striatum.

\section{Cortical projections}

Frontal motor areas containing dense cell labeling included the ventral PM, Pre-SMA, and rostral CMA (Table 1). There were many WGA-positive cells throughout both the caudal and rostral divisions of PMv. In contrast to dorsal putamen injections, there were no WGA-positive cells in the medial M1 or PMd. WGA- 


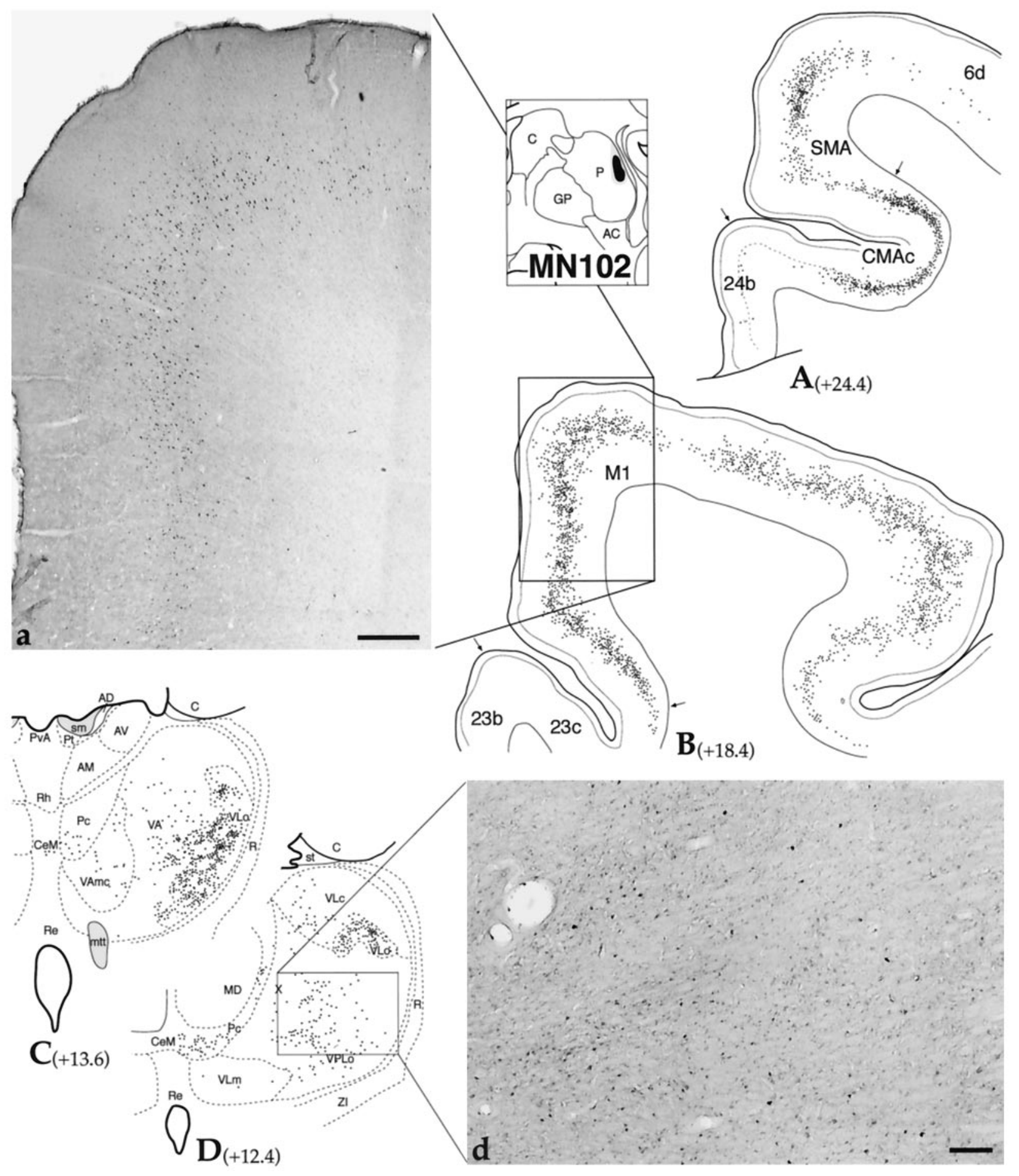

Figure 4. Case MN102. A, B, Cortical schematics showing the distribution of WGA-positive neurons in motor cortical areas after tracer injection into the dorsolateral putamen (striatal schematic depicts site). $a$, Photomicrograph of WGA-positive cells in M1 shown in boxed area of $A$. Scale bar, 0.5 mm. $C, D$, Coronal hemisections through the VA/VL complex of the thalamus illustrating the distribution of retrogradely labeled cells. $d$, Photomicrograph of WGA-positive cells in VPLo shown in boxed area of $D$. Scale bar, $0.25 \mathrm{~mm}$. Numbers next to labels indicate approximate AP level, relative to interaural zero. For cortical and thalamic abbreviations, see legends in Figures 2 and 3, respectively. $A C$, Anterior commissure; $C$, caudate nucleus; $G P$, globus pallidus; $P$, putamen.

immunoreactive cells in PMv extended from the arcuate sulcus ventrally into the precentral opercular area spanning the width of layer V (Figs. 8C-E). Caudally, labeled cells in PMvc extended partly into the face area of M1. There was also a relatively small but dense group of WGA-positive cells in the caudal, dorsal part of Pre-SMA (Fig. 8B). In addition, there was a separate, moderately dense group of labeled cells in the ventral bank of the cingulate sulcus in CMAr (Fig. $8 A, B$ ). 

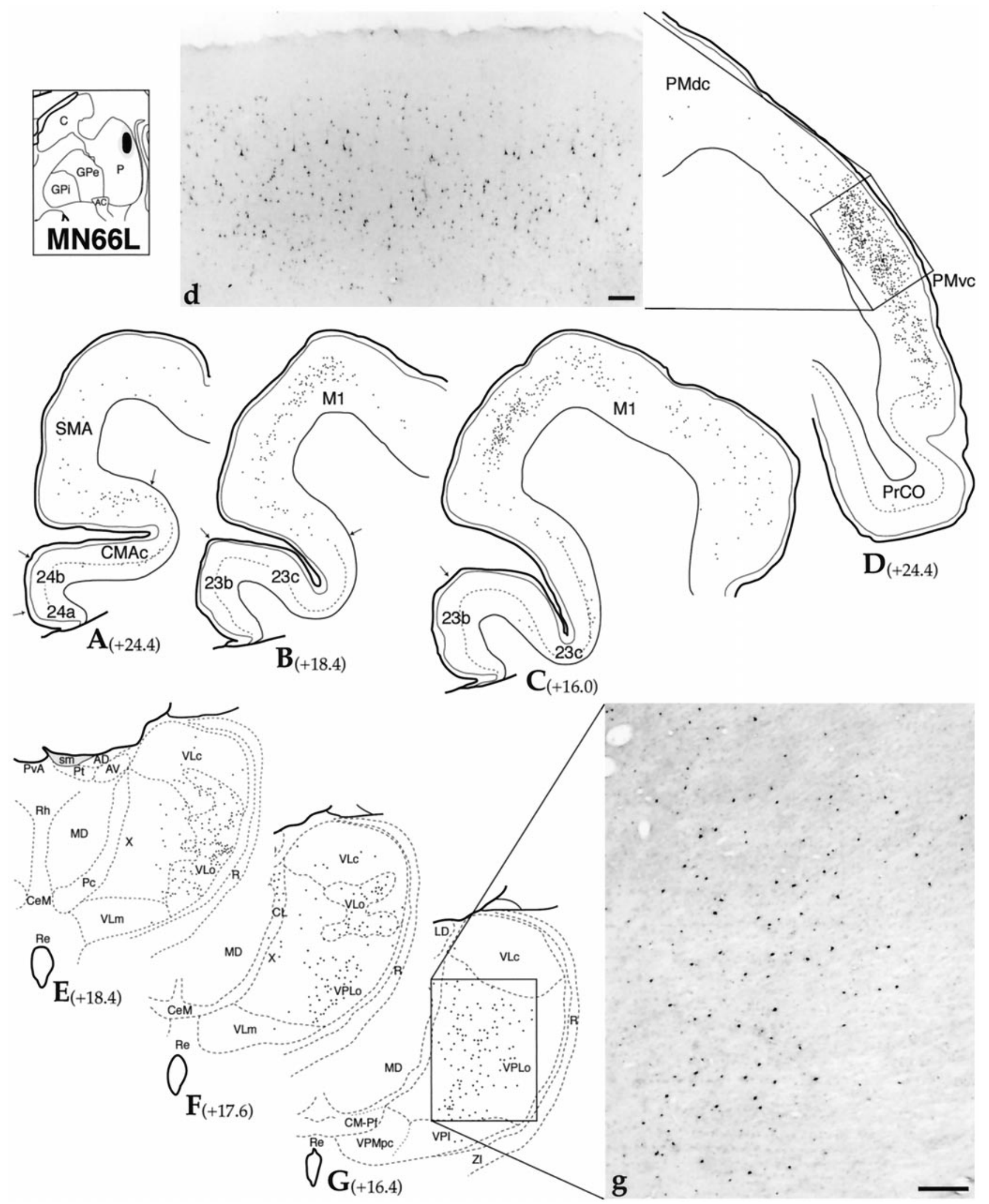

Figure 5. Case MN66L. A-D, Cortical schematics showing the distribution of LY-positive neurons in motor cortical areas after tracer injection into the dorsolateral putamen (striatal schematic depicts site). $c$, Macro-photograph of LY-positive cells in PMvc shown in boxed area of $C$. Scale bar, 0.5 mm. $E-G$, Coronal hemisections through the VA/VL complex of the thalamus illustrating the distribution of retrogradely labeled cells. $g$, Macro-photograph of LY-positive cells in VPLo shown in boxed area of $G$. Scale bar, $0.25 \mathrm{~mm}$. Numbers next to labels indicate approximate AP level, relative to interaural zero. For cortical and thalamic abbreviations, see legends in Figures 2 and 3, respectively. $A C$, Anterior commissure; $C$, caudate nucleus; $G P e / i$, globus pallidus, external/internal segments; $P$, putamen. 

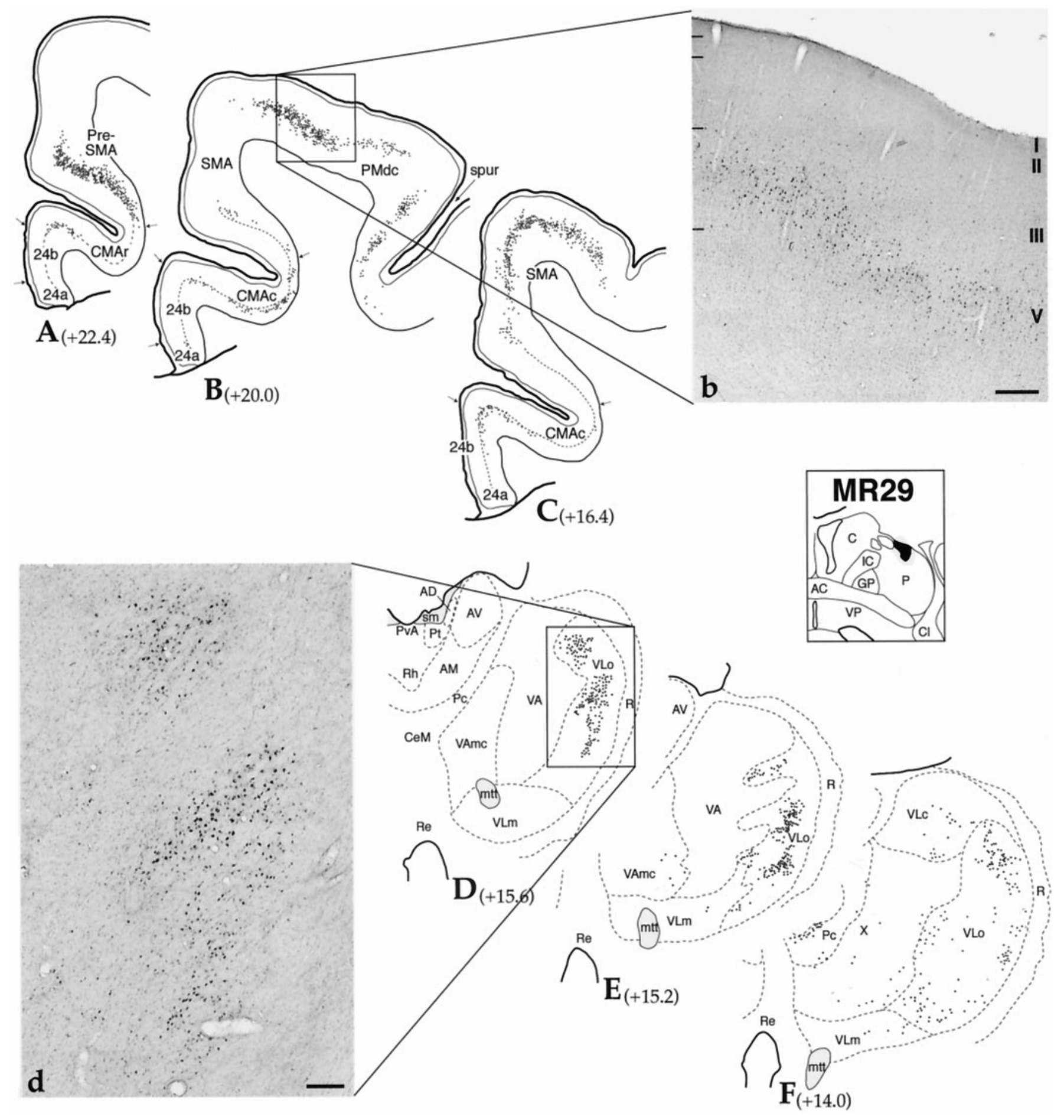

Figure 6. Case MR29. A-C, Cortical schematics showing the distribution of WGA-positive neurons in motor cortical areas after tracer injection into the dorsal putamen (striatal schematic depicts site). $b$, Macro-photograph of WGA-positive cells in PMdc shown in boxed area of $B$. Scale bar, 0.5 mm. $D-F$, Coronal hemisections through the VA/VL complex of the thalamus illustrating the distribution of retrogradely labeled cells. $d$, Photomicrograph of WGA-positive cells in VLo shown in boxed area of $D$. Scale bar, $0.25 \mathrm{~mm}$. Numbers next to labels indicate approximate AP level, relative to interaural zero. For cortical and thalamic abbreviations, see legends in Figures 2 and 3, respectively. $A C$, Anterior commissure; $C$, caudate nucleus; $C l$, claustrum; $G P$, globus pallidus; $I C$, internal capsule; $P$, putamen; $V P$, ventral pallidum.

\section{Ventral thalamic projections}

In contrast to other dorsolateral cases, the densest retrograde labeling in case MN39 was not found in VLo but rather in the parvicellular, VA nucleus (Table 2). There were many WGA-positive cells in the ventromedial part of the caudal VA, near the border of the magnocellular division of VA (Figs. $8 F, G, V A m c$ ). More caudally there was an isolated, small group of WGA-immunoreactive cells in the dorsomedial part of the rostral VLo (Fig. $8 H$ ).

\section{Projections to the dorsolateral caudate nucleus}

Case MN32 included a WGA-HRP injection into the dorsolateral head of the caudate nucleus. 

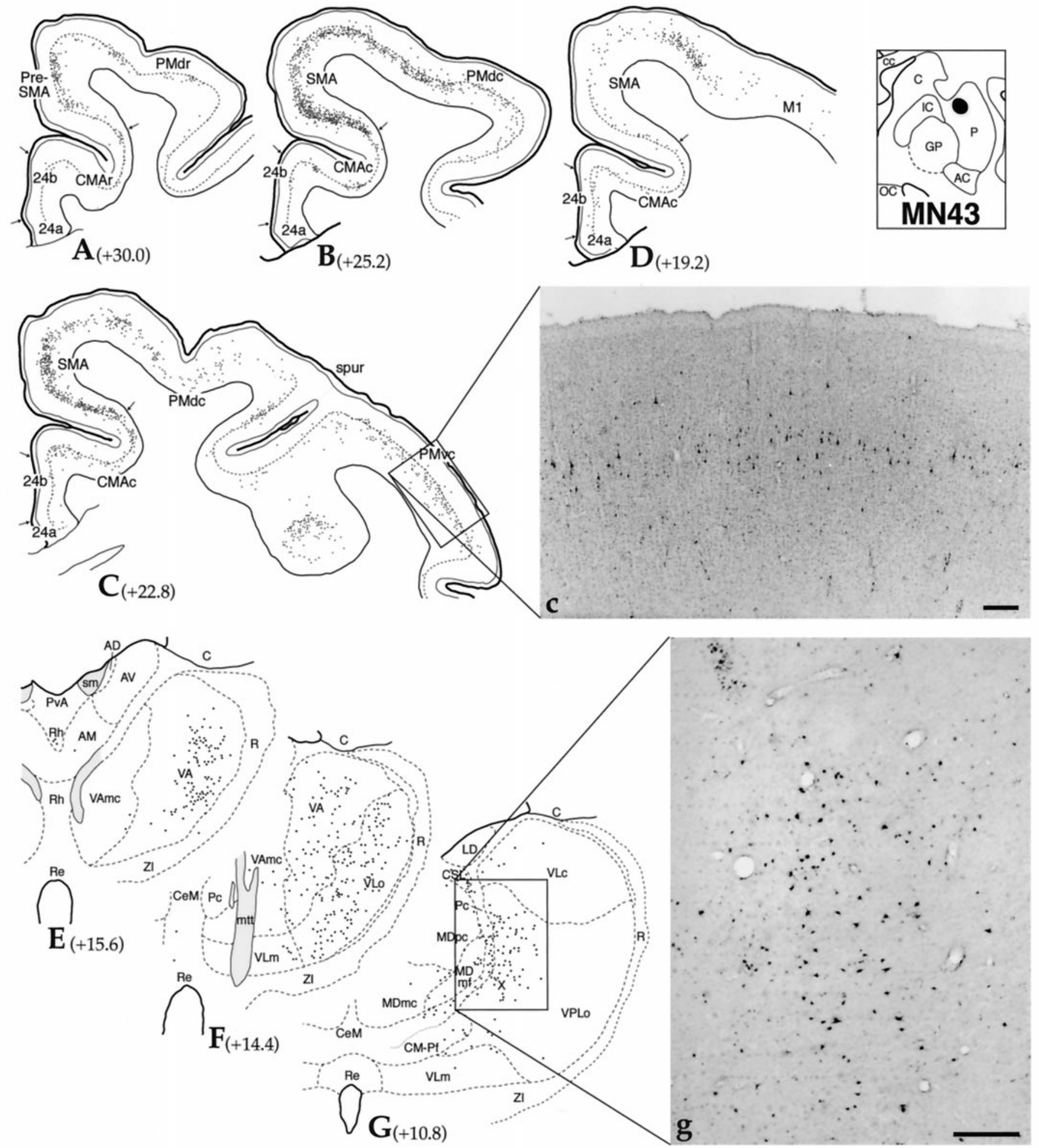

Figure 7. Case MN43. A-D, Cortical schematics showing the distribution of LY-positive neurons in motor cortical areas after tracer injection into the dorsal, central putamen (striatal schematic depicts site). c, Macro-photograph of LY-positive cells in PMvc shown in boxed area of $C$. Scale bar, $0.5 \mathrm{~mm}$. $E-G$, Coronal hemisections through the VA/VL complex of the thalamus illustrating the distribution of retrogradely labeled cells. $g$, Photomicrograph of LY-positive cells in Area X shown in boxed area of $G$. Scale bar, $0.5 \mathrm{~mm}$. Numbers next to labels indicate approximate AP level, relative to interaural zero. For cortical and thalamic abbreviations, see legends in Figures 2 and 3, respectively. $A C$, Anterior commissure; $C$, caudate nucleus; $G P$, globus pallidus; $I C$, internal capsule; $O C$, optic chiasm; $P$, putamen. 

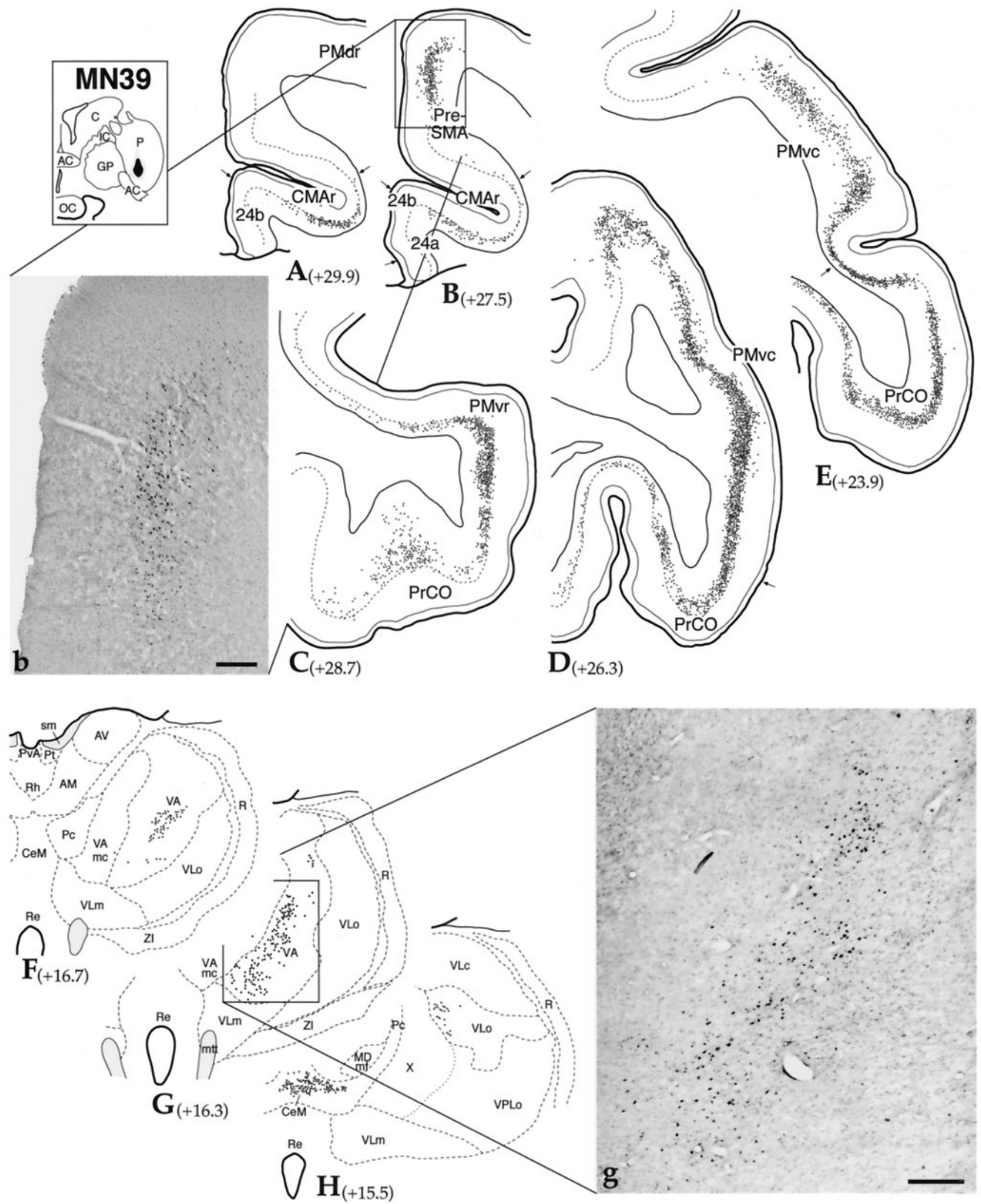

Figure 8. Case MN39. A-E, Cortical schematics showing the distribution of WGA-positive neurons in motor cortical areas after tracer injection into the ventral putamen (striatal schematic depicts site). $b$, Macro-photograph of WGA-positive cells in Pre-SMA shown in boxed area of $B$. Scale bar, 0.5 mm. $F-H$, Coronal hemisections through the VA/VL complex of the thalamus illustrating the distribution of retrogradely labeled cells. $g$, Photomicrograph of WGA-positive cells in VA shown in boxed area of $G$. Scale bar, $0.5 \mathrm{~mm}$. Numbers next to labels indicate approximate AP level, relative to interaural zero. For cortical and thalamic abbreviations, see legends in Figures 2 and 3, respectively. $A C$, Anterior commissure; $C$, caudate nucleus; $G P$, globus pallidus; $I C$, internal capsule; $O C$, optic chiasm; $P$, putamen. 


\section{Cortical projections}

In contrast to dorsal putamen injections, dense cortical labeling was primarily limited to rostral, motor cortical areas (Table 1). There were dense groups of WGA-positive cells in PMdr and Pre-SMA. Two dense groups of labeled cells were identified in PMdr: one located centrally in the dorsal convexity and the other within the dorsal bank of the arcuate sulcus (Fig. 9B). Labeled cells in PMdr extended caudally into part of PMdc. In Pre-SMA, dense WGA labeling was located in the rostral, ventral part of the medial wall and extended into the dorsal bank of the cingulate sulcus (Fig. 9A). There were scattered WGA-positive cells along the medial wall of the cingulate gyrus (area 24b).

\section{Ventral thalamic projections}

The densest concentrations of labeled cells were located in VLo and VLc (Table 2). There were many WGA-positive cells in the rostral, central part of VLo (Fig. 9D). Caudally, labeled cells in VLo were more scattered but occupied most of the nucleus. Cell labeling in VLc was densest in the rostral and medial part of the nucleus (Fig. 9E). In contrast to other dorsal striatal injections, there were no labeled cells in VPLo or Area X. Rostrally, there were a few WGA-immunoreactive cells in the rostral, lateral portion of the parvicellular division of VA.

\section{DISCUSSION}

We examined the organization of ventral tier thalamic inputs to the motor striatum to determine how this afferent projection is organized with respect to corticostriatal afferents from motor and premotor areas. Specific dorsal striatal regions received frontal cortical projections from several anatomically distinct but functionally related motor areas. The dorsal striatum also received dense projections from the ventral anterior and ventral lateral thalamic nuclei. Ventral thalamostriatal projections are significant in that VA/VL nuclei are primarily thought to relay basal ganglia and cerebellar output to the frontal cortex (Asanuma et al., 1983; Schell and Strick, 1984; Alexander et al., 1990; Rouiller et al., 1994; Sakai et al., 1996). Ventral thalamic motor nuclei have differential connections with these motor cortical areas (Wiesendanger and Wiesendanger, 1985; Matelli et al., 1989; Dum and Strick, 1993; Matelli and Luppino, 1996). Our results provide evidence for convergent striatal projections from interconnected ventral thalamic and frontal cortical motor areas, suggesting that these striatal afferents modulate the same striatal output circuits.

\section{Organization and function of corticostriatal projections to the dorsal motor striatum}

Dorsal striatal injections labeled neurons in several, distinct motor-related areas, including the M1, SMA, PM, and CMA cortices (Table 1). The presence of labeled cells in anatomically distinct frontal cortical areas supports the notion of convergent corticostriatal motor circuits. Yeterian and Van Hoesen (1978) proposed that reciprocally interconnected cortical areas send convergent, overlapping projections to the striatum. Subsequently, Selemon and Goldman-Rakic (1985) found that although reciprocally interconnected cortical areas project to the same regions of the striatum, their patchwork of terminals interdigitates, suggesting that cortical afferents remain segregated. More recent studies provide evidence for overlapping corticostriatal projections from both reciprocally and weakly interconnected cortical areas (Parthasarathy et al., 1992; Flaherty and Graybiel, 1993; Inase et al., 1996; Takada et al., 1998a,b). There are substantial interconnections between M1, SMA, PM, and CMA cortices (Muakkassa and Strick, 1979; Godschalk et al., 1984; Matelli et al., 1984, 1986; Barbas and Pandya, 1987; Luppino et al., 1990; Morecraft and Van Hoesen, 1992; Dum and Strick, 1993; Luppino et al., 1993; Lu et al., 1994). However, not all of these cortical areas have overlapping terminal fields within the striatum. Recent anterograde studies show some overlap of somatotopic projections from M1 and SMA, and SMA and PM areas, but segregated terminals from M1 and PM areas within the putamen. Furthermore, although there is overlap of terminals from M1 and SMA, the densest projections to the putamen are largely segregated (Inase et al., 1996; Takada et al., 1998b). Thus, although some projections from interconnected frontal cortical areas overlap, their primary projections remain segregated within the striatum. The present study demonstrates that discrete dorsal striatal sites receive projections from several distinct motor cortical areas, indicating convergence. However, each region of the dorsal striatum received a different set of motor cortical afferents, suggesting some segregation (Fig. 10A). Furthermore, differential motor cortical inputs to discrete dorsal striatal regions indicate that integration of specific aspects of motor control occurs at the level of the striatum.

To further characterize the functional organization of motor cortical inputs to the dorsal striatum, we analyzed the relative distributions of cortical inputs to each site from all motor-related areas in the frontal cortex (Table 1). We organized motor areas in increasing order of their involvement in "higher-order" cognitive motor processing and decreasing order of direct involvement in movement execution based on anatomical (i.e., intercortical connections) and neurophysiological (i.e., relationship to different aspects of motor control) studies. Caudal motor areas, including M1, SMA, CMAc, and caudal PM areas, have descending corticospinal projections that closely modulate lower-motor neuron output and are primarily involved in the specifics of movement execution (Hutchins et al., 1988; Dum and Strick, 1991; He et al., 1993, 1995; Luppino et al., 1994). In contrast, rostral motor areas, such as Pre-SMA and CMAr, do not project to the spinal cord and have few connections with M1 (Muakkassa and Strick, 1979; Shima et al., 1991). These areas are connected with prefrontal cognitive and limbic cortical regions and are most active during learning of motor tasks and respond to rewards (Bates and Goldman-Rakic, 1993; Morecraft and VanHoesen, 1993; Lu et al., 1994; Nakamura et al., 1998; Shima and Tanji, 1998). Intermediate motor areas, such as SMA and PM, appear to direct specific aspects of complex motor activities, including bimanual, reaching, grasping, and sequenced movements in relation to internal states or external stimuli (Kurata and Wise, 1988; Mushiake et al., 1991; Tanji and Shima, 1994; Fogassi et al., 1996; Graziano et al., 1997). Thus, although all motor-related cortical areas participate in motor control, they are organized such that there is a rostral-caudal functional hierarchy. Rostral areas primarily process cognitive aspects of motor control, whereas caudal areas are more directly involved in movement execution.

Motor cortical projections to the dorsal striatum maintain this functional hierarchy. Dorsolateral putamen injections showed dense labeling in caudal motor areas such as M1, caudal PMvc, and CMAc, whereas ventral putamen and dorsolateral caudate injections labeled rostral motor areas such as PMvr, PMdr, PreSMA and CMAr (Table 1). Central injections in the dorsal striatum received a mixture of caudal and rostral motor cortical inputs from SMA, PMd, PMv, and Pre-SMA. These results demonstrate that functionally related motor and premotor areas have convergent projections to specific regions of the dorsal 


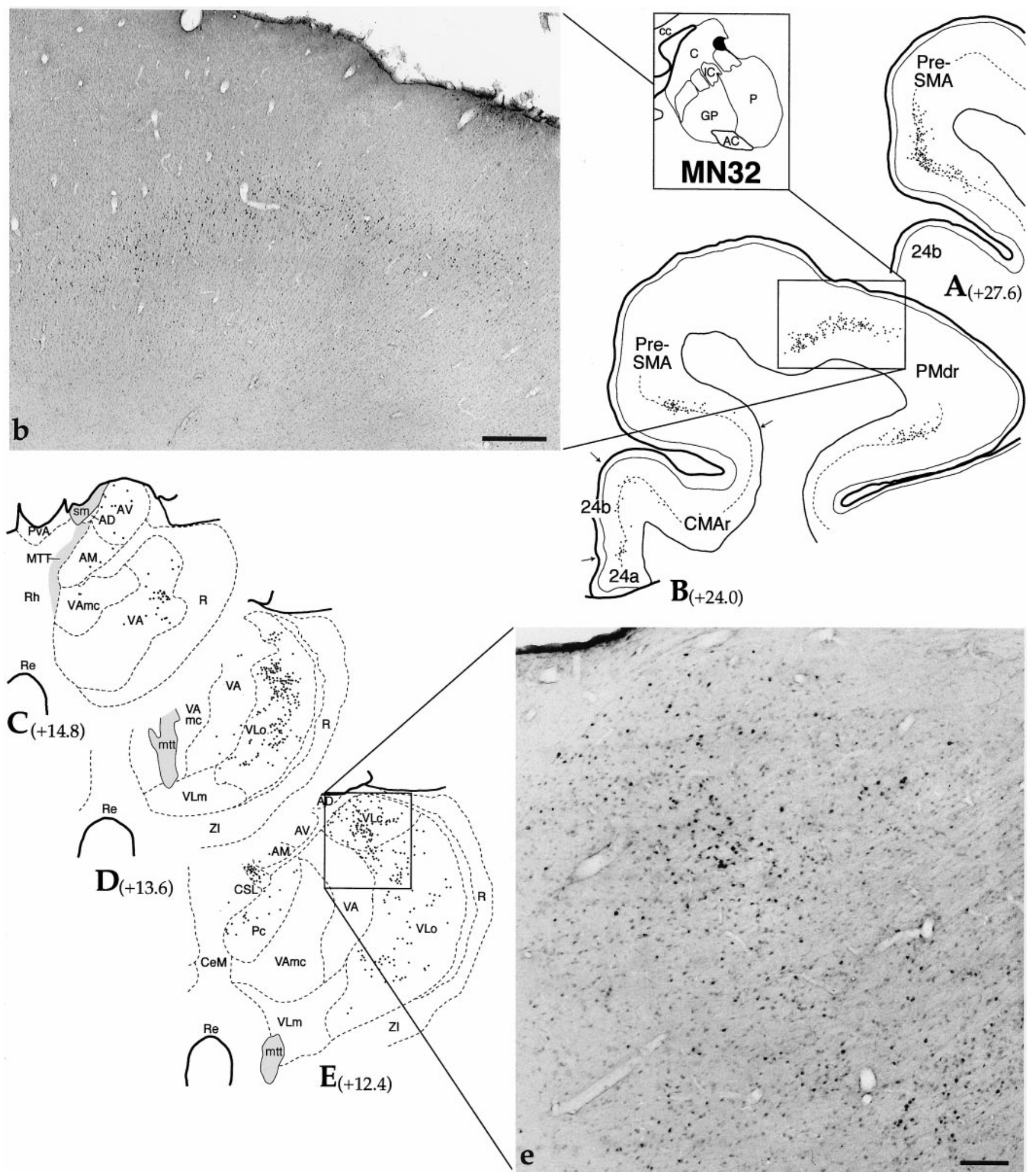

Figure 9. Case MN32. A, B, Cortical schematics showing the distribution of WGA-positive neurons in motor cortical areas after tracer injection into the dorsolateral caudate nucleus (striatal schematic depicts site). $b$, Macro-photograph of WGA-positive cells in PMdr shown in boxed area of $B$. Scale bar, $0.5 \mathrm{~mm}$. $C-E$, Coronal hemisections through the VA/VL complex of the thalamus illustrating the distribution of retrogradely labeled cells after tracer injection into the dorsolateral caudate nucleus (striatal schematic depicts site). $e$, Macro-photograph of WGA-positive cells in VLc shown in boxed area of $E$. Scale bar, $0.25 \mathrm{~mm}$. Numbers next to labels indicate approximate AP level, relative to interaural zero. For cortical and thalamic abbreviations, see legends in Figures 2 and 3, respectively. $A C$, Anterior commissure; $C$, caudate nucleus; $G P$, globus pallidus; $I C$, internal capsule; $P$, putamen. 

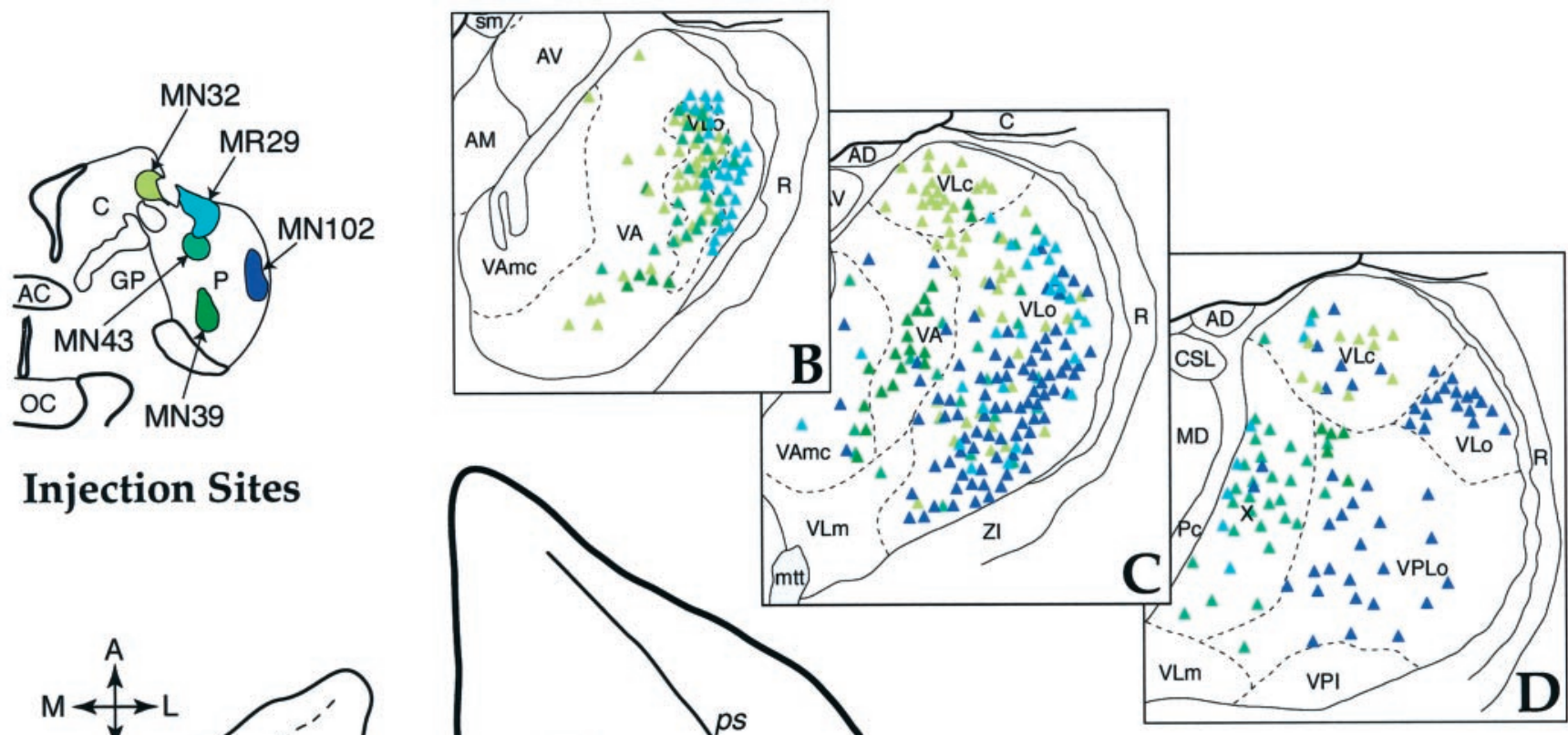

\section{Injection Sites}

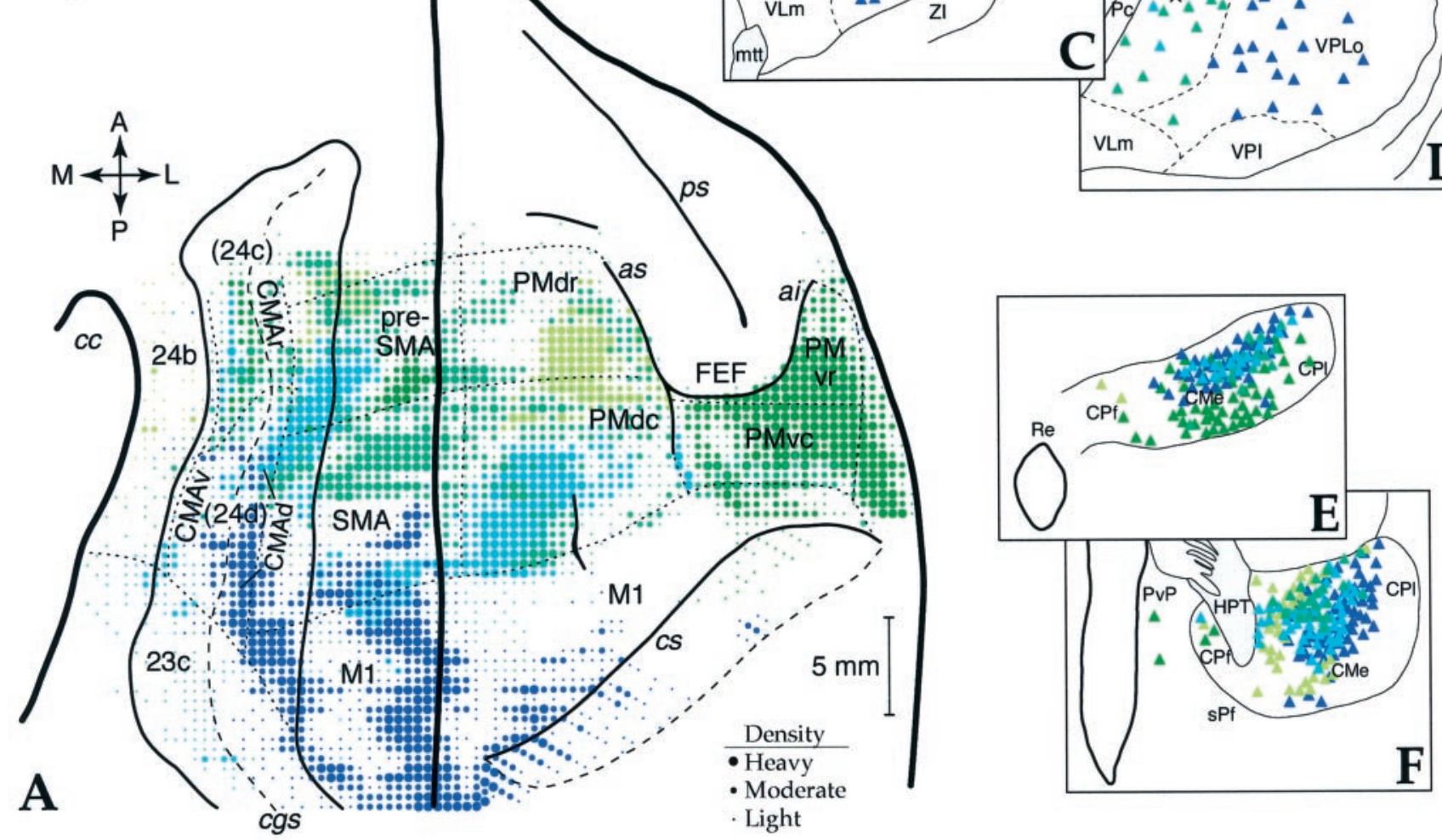

Figure 10. A, Surface plot of the relative density of labeled corticostriatal cells comparing the distribution of motor cortical projections with dorsal striatal sites (colors correspond to injections in striatal schematic above). $B-D$, Rostral to caudal schematics through the VA/VL complex summarizing the relative distributions of thalamostriatal neurons projecting to the same dorsal striatal sites. $E, F$, Schematics summarizing the distribution of labeled cells at rostral and caudal levels of the CM-Pf, or central, complex. For cortical and thalamic abbreviations, see legends in Figures 2 and 3, respectively. $A C$, Anterior commissure; $C$, caudate nucleus; $C M e, C P l, C P f$, central complex, pars media, pars lateralis, and pars parafascicularis, respectively; $G P$, globus pallidus; $O C$, optic chiasm; $P$, putamen.

striatum and suggest that these regions may integrate information regarding particular aspects of motor control, such as motor learning and movement execution. Predominately caudal motor afferents to the dorsolateral putamen are consistent with physiological studies indicating that this region processes information closely linked to aspects of movement execution (Crutcher and DeLong, 1984; Alexander and DeLong, 1985; DeLong et al., 1986; Alexander and Crutcher, 1990). Although neurons in the dorsolateral putamen show activity linked to movement onset, striatal neurons in the dorsomedial putamen and dorsolateral head of the caudate nucleus demonstrate premovement activity during cued tasks (Kimura, 1990; Gardiner and Nelson, 1992). SMA projections primarily targeted the central, dorsal putamen, whereas PMv inputs mainly targeted the ventral putamen, sug- gesting that these striatal regions may differentially processes internally versus externally guided (i.e., visual) movements. PMdr and Pre-SMA inputs to the dorsolateral caudate suggest that this region may process more cognitive aspects of motor control, such as those prominent during motor learning. Consistent with these findings, activity of striatal neurons in the head of the caudate nucleus during learning of sequential hand movements is greater than that in the putamen (Miyachi et al., 1997).

\section{Organization of ventral thalamostriatal projections to the motor striatum}

Both the ventral thalamic motor nuclei and the CM-Pf complex project topographically to the dorsal striatum. Although thalamostriatal projections from CM-Pf have been extensively studied 
(Fénelon et al., 1991; Francois et al., 1991; Sadikot et al., 1992a; Giménez-Amaya et al., 1995), there are few reports of significant thalamostriatal projections from the ventral motor nuclei (Smith and Parent, 1986; Nakano et al., 1990; Druga et al., 1991). VLo and VApc nuclei are primarily thought to relay pallidal output to motor cortical areas (Schell and Strick, 1984; Ilinsky and KultasIlinsky, 1987; Rouiller et al., 1994; Sakai et al., 1996; Hoover and Strick, 1999). Although the CM-Pf complex also receives input from the pallidum (Kuo and Carpenter, 1973; Kim et al., 1975; DeVito and Anderson, 1982; Parent and DeBellefeuille, 1983) and the substantia nigra (Ilinsky et al., 1985), it is not thought play a major role in relaying basal ganglia output to the frontal cortex. Our results indicate that VA/VL thalamostriatal projections constitute a major portion of thalamic afferents to the dorsal striatum, comparable to that from CM-Pf. The existence of direct VA/VL projections to the dorsal motor striatum suggests that ventral thalamic nuclei modulate corticobasal ganglia motor circuits and provide another route for striatal feedback.

In addition to VA and VLo nuclei, ventral thalamic projections to the dorsal striatum also arose from VPLo, VLc, and Area X. These nuclei primarily relay cerebellar output to the frontal cortex (Percheron, 1977; Kalil, 1981; Asanuma et al., 1983; Schell and Strick, 1984). All dorsal striatal sites, with the exception of the most ventral injection, received inputs from thalamic, cerebellar relay nuclei (Table 2). Recent data suggest that cerebellar and basal ganglia circuits through the thalamus are not entirely segregated. Although the SMA and primary motor cortices were thought to receive separate VLo and VPLo inputs, respectively, several studies indicate overlap of VLo/VPLo inputs to these cortical areas (Matelli et al., 1989; Holsapple et al., 1991; Nambu et al., 1991; Hoover and Strick, 1993, 1999). Moreover, there is also some evidence for overlap of pallidothalamic and cerebellothalamic terminals in VLo, VLc, and Area X (Sakai et al., 1996). Thus, like motor cortical areas, all dorsal striatal sites may receive contributions from both pallidal- and cerebellar-receiving, ventral thalamic nuclei. Thalamostriatal projections from VPLo, VLc, and Area X provide the first evidence for cerebellar inputs to the basal ganglia, specifically influencing motor circuits impinging on the dorsal striatum.

\section{Convergent dorsal striatal afferents from interconnected ventral thalamic and motor cortical areas: functional implications}

Ventral thalamic motor areas are intimately connected with frontal cortical motor areas (Wiesendanger and Wiesendanger, 1985; Matelli et al., 1989; Nakano et al., 1992; Dum and Strick, 1993; Matelli and Luppino, 1996). Our findings indicate that interconnected ventral thalamic and cortical motor areas project to the same region of the dorsal striatum (Fig. 10). VPLo projects to M1 and most of the caudal "secondary" motor areas. These areas issue dense projections to the dorsolateral putamen. VLo projects densely to SMA and the dorsal part of CMAc. VLo and SMA projections converged in the dorsal, central putamen. VLc is predominately connected with PMd, but also has connections with PMv and the ventral part of CMAc. VLc and PMd projections mainly target the dorsolateral caudate nucleus. Rostral motor areas, including PMdr, Pre-SMA, and CMAr, receive inputs from VApc. Striatal projections from these areas converge within the ventral putamen and dorsolateral caudate. These findings suggest that interconnected ventral thalamic and cortical motor areas modulate the same striatal output circuits and pro-

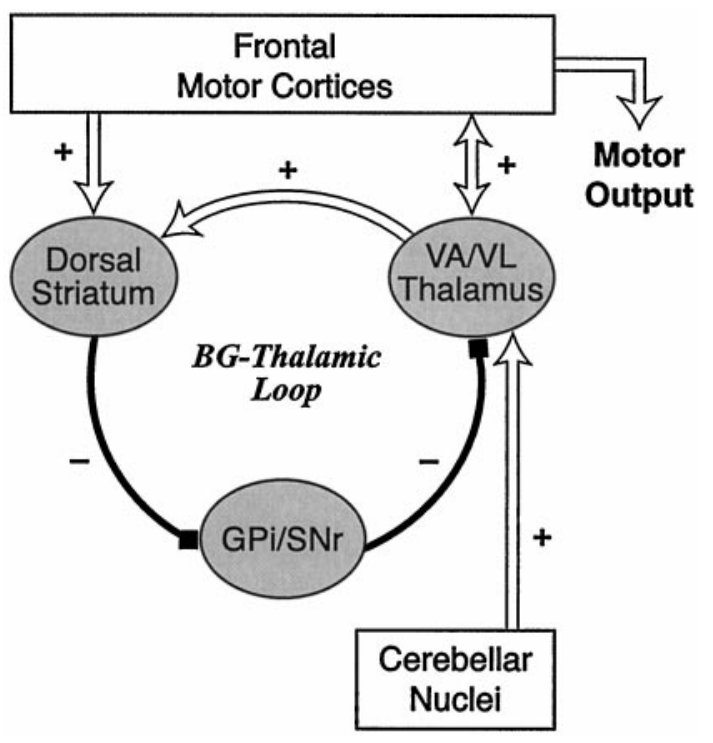

Figure 11. Illustration of the subcortical basal ganglia-thalamic loop involving VA/VL thalamostriatal projections to the dorsal striatum. Open and black lines represent excitatory and inhibitory connections, respectively. Direct VA/VL projections to the dorsal striatum provide positive feedback, resulting in sustained disinhibition of thalamocortical output. Ventral thalamostriatal projections may also provide a route for cerebellar information to influence basal ganglia motor circuits.

vide another mechanism for integration of motor information in the striatum.

The present study demonstrates a tight, anatomical and functional triad of basal ganglia input and output structures involving the frontal motor cortices, the dorsal striatum, and the ventral thalamic motor nuclei. Our findings clearly show that ventral thalamic projections play a dual role in basal ganglia circuitry: (1) relaying basal ganglia output to frontal cortical areas and (2) providing direct feedback to the striatum. Traditional models of basal ganglia function, however, emphasize the VA/VL thalamocortical projection. In these models, basal ganglia output disinhibits VA/VL thalamocortical circuits, resulting in the release of motor responses (DeLong, 1990; Parent and Hazrati, 1995; Wichmann and DeLong, 1996). Reciprocal corticothalamic projections in this system have been suggested to provide positive feedback, serving as a "working memory" for the information encoded by the basal ganglia for a selected behavior (Houk and Wise, 1995). The existence of ventral thalamostriatal projections raises the possibility that VA/VL projections also provide positive feedback, but to the striatum (Fig. 11). We propose that positive feedback from VA/VL thalamostriatal projections functions to reinforce basal ganglia motor circuits necessary for performing a selected behavior. Although relatively unexplored, studies indicate that thalamostriatal inputs are excitatory and target mediumspiny neurons, or striatal output neurons, supporting a positive modulatory affect (Wilson et al., 1983; Dubé et al., 1988; Sadikot et al., 1992b). Striatal feedback from VA/VL nuclei would therefore sustain disinhibition of specific thalamocortical circuits, which would release motor responses and keep a behavior "on task" until its goal is achieved. Alternatively, such feedback may further reinforce or facilitate selection of basal ganglia circuits that enable desired and suppress unwanted movements (Mink and Thach, 1991). 


\section{REFERENCES}

Alexander GE, Crutcher MD (1990) Preparation for movement: neural representations of intended direction in three motor areas of the monkey. J Neurophysiol 64:133-150.

Alexander GE, DeLong MR (1985) Microstimulation of the primate neostriatum. II. Somatotopic organization of striatal microexcitable zones and their relation to neuronal response properties. J Neurophysiol 53:1417-1430.

Alexander GE, Crutcher MD, DeLong MR (1990) Basal gangliathalamocortical circuits: parallel substrates for motor, oculomotor, "prefrontal" and "limbic" functions. Prog Brain Res 85:119-146.

Asanuma C, Thach WT, Jones EG (1983) Distribution of cerebellar terminations and their relation to other afferent terminations in the ventral lateral thalamic region of the monkey. Brain Res 286:237-265.

Barbas H, Pandya DN (1987) Architecture and frontal cortical connections of the premotor cortex (area 6) in the rhesus monkey. J Comp Neurol 256:211-228.

Bates JF, Goldman-Rakic PS (1993) Prefrontal connections of medial motor areas in the rhesus monkey. J Comp Neurol 336:211-228.

Carpenter MB (1989) Connectivity patterns of thalamic nuclei implicated in dyskinesia. Stereotact Funct Neurosurg 52:79-119.

Crutcher MD, DeLong MR (1984) Single cell studies of the primate putamen II. Relations to direction of movement and pattern of muscular activity. Exp Brain Res 53:244-258.

DeLong MR (1990) Primate models of movement disorders of basal ganglia origin. Trends Neurosci 13:281-285.

DeLong MR, Alexander GE, Mitchell SJ, Richardson RT (1986) The contribution of basal ganglia to limb control. In: Progress in brain research (Freund H-J, Buttner U, Cohen B, Noth J, eds), pp 161-174. New York: Elsevier.

DeVito JL, Anderson ME (1982) An autoradiographic study of efferent connections of the globus pallidus in Macaca mulatta. Exp Brain Res 46:107-117.

Druga R, Rokyta R, Benes V (1991) Thalamocaudate projections in the macaque monkey (a horseradish peroxidase study). J Hirnforsch 6:765-774.

Dubé L, Smith AD, Bolam JP (1988) Identification of synaptic terminals of thalamic or cortical origin in contact with distinct medium-size spiny neurons in the rat neurostriatum. J Comp Neurol 267:455-471.

Dum RP, Strick PL (1991) The origin of corticospinal projections from the premotor areas in the frontal lobe. J Neurosci 11:667-689.

Dum RP, Strick PL (1993) Cingulate motor areas. In: Neurobiology of cingulate cortex and limbic thalamus: a comprehensive treatise (Vogt BA, Gabriel M, eds), pp 415-441. Boston: Birkhauser.

Fénelon G, Francois C, Percheron G, Yelnik J (1991) Topographic distribution of the neurons of the central complex (centre medianparafascicular complex) and of other thalamic neurons projecting to the striatum in macaques. Neuroscience 45:495-510.

Flaherty AW, Graybiel AM (1993) Two input systems for body representations in the primate striatal matrix: experimental evidence in the squirrel monkey. J Neurosci 13:1120-1137.

Fogassi L, Gallese V, Fadiga L, Luppino G, Matelli M, Rizzolatti G (1996) Coding of peripersonal space in inferior premotor cortex (area F4). J Neurophysiol 76:141-157.

Francois C, Percheron G, Parent A, Sadikot AF, Fenelon G, Yelnik J (1991) Topography of the projection from the central complex of the thalamus to the sensorimotor striatal territory in monkeys. J Comp Neurol 305:17-34.

Gardiner TW, Nelson RJ (1992) Striatal neuronal activity during the initiation and execution of hand movements made in response to visual and vibratory cues. Exp Brain Res 92:15-26.

Giménez-Amaya JM, McFarland NR, de las Heras S, and Haber SN (1995) Organization of thalamic projections to the ventral striatum in the primate. J Comp Neurol 354:127-149.

Godschalk M, Lemon RN, Kuypers HGJM, Ronday HK (1984) Cortical afferents and efferents of monkey postarcuate area: an anatomical and electrophysiological study. Exp Brain Res 56:410-424.

Graziano MS, Hu XT, Gross CG (1997) Visuospatial properties of ventral premotor cortex. J Neurophysiol 77:2268-2292.

Haber SN, Lynd-Balta E, Mitchell SJ (1993) The organization of the descending ventral pallidal projections in the monkey. J Comp Neurol 329:111-129.

Haber SN, Lynd-Balta E, Spooren WPTM (1994) Integrative aspects of basal ganglia circuitry. In: The basal ganglia IV (G. P, J.S. M, and J. F, eds), pp 71-80. New York: Plenum Press.
Hassler R (1959) Anatomy of the thalamus. In: Introduction to stereotaxic operations with and atlas of the human brain (Schaltenbrand $\mathrm{G}$, Baily P, eds), pp 230-290. Stuttgart: Thieme.

He S-Q, Dum RP, Strick PL (1993) Topographic organization of corticospinal projections from the frontal lobe: motor areas on the lateral surface of the hemisphere. J Neurosci 13:952-980.

He SQ, Dum RP, Strick PL (1995) Topographic organization of corticospinal projections from the frontal lobe: motor areas on the medial surface of the hemisphere. J Neurosci 15:3284-3306.

Holsapple JW, Preston JB, Strick PL (1991) The origin of thalamic inputs to the "hand" representation in the primary motor cortex. J Neurosci 11:2644-2654.

Hoover JE, Strick PL (1993) Multiple output channels in the basal ganglia. Science 259:819-821.

Hoover JE, Strick PL (1999) The organization of cerebellar and basal ganglia outputs to primary motor cortex as revealed by retrograde transneuronal transport of herpes simplex virus type 1 . J Neurosci 19:1446-1463.

Houk JC, Wise SP (1995) Distributed modular architectures linking basal ganglia, cerebellum, and cerebral cortex: their role in planning and controlling action. Cereb Cortex 5:95-110.

Hutchins KD, Martino AM, Strick PL (1988) Corticospinal projections from the medial wall of the hemisphere. Exp Brain Res 71:667-672.

Ilinsky IA, Kultas-Ilinsky K (1987) Sagittal cytoarchitectonic maps of the Macaca mulatta thalamus with a revised nomenclature of the motor-related nuclei validated by observations on their connectivity. J Comp Neurol 262:331-364.

Ilinsky IA, Jouandet ML, Goldman-Rakic PS (1985) Organization of the nigrothalamocortical system in the rhesus monkey. J Comp Neurol 236:315-330

Inase M, Sakai ST, Tanji J (1996) Overlapping corticostriatal projections from the supplementary motor area and the primary motor cortex in the Macaque monkey: an anterograde double labeling study. J Comp Neurol 373:283-296.

Jones EG (1985) The thalamus. New York: Plenum.

Jones EG, Hendry SHC (1989) Differential calcium binding protein immunoreactivity distinguishes classes of relay neurons in monkey thalamic nuclei. Eur J Neurosci 1:223-246.

Jones EG, Leavitt RY (1974) Retrograde axonal transport and the demonstration of non-specific projections to the cerebral cortex and striatum from thalamic intralaminar nuclei in the rat, cat and monkey. J Comp Neurol 154:349-378.

Kalil K (1981) Projections of the cerebellar and dorsal column nuclei upon the thalamus of the rhesus monkey. J Comp Neurol 195:25-50.

Kim R, Nakano K, Jayaraman A, Carpenter MB (1975) Projections of the globus pallidus and adjacent structures: an autoradiographic study in the monkey. J Comp Neurol 169:263-290.

Kimura M (1990) Behaviorally contingent property of movementrelated activity of the primate putamen. J Neurophysiol 63:1277-1296.

Kimura M, Aosaki T, Hu Y, Watanabe K (1992) Activity of primate neurons is selective to the mode of voluntary movement: visually guided, self-initiated or memory-guided. Exp Brain Res 89:472-477.

Kuo J, Carpenter MB (1973) Organization of pallidothalamic projections in the rhesus monkey. J Comp Neurol 151:201-236.

Kurata K (1993) Premotor cortex of monkeys: set- and movementrelated activity reflecting amplitude and direction of wrist movements. J Neurophysiol 69:187-200.

Kurata K (1994) Site of origin of projections from the thalamus to dorsal versus ventral aspects of the premotor cortex of monkeys. Neurosci Res 21:71-76.

Kurata K, Hoffman DS (1994) Differential effects of muscimol microinjection into dorsal and ventral aspects of the premotor cortex of monkeys. J Neurophysiol 71:1151-1164.

Kurata K, Wise SP (1988) Premotor and supplementary motor cortex in rhesus monkeys: neuronal activity during externally- and internallyinstructed motor tasks. Exp Brain Res 72:237-248.

Lu M-T, Preston JB, Strick PL (1994) Interconnections between the prefrontal cortex and the premotor areas in the frontal lobe. J Comp Neurol 341:375-392.

Luppino G, Matelli M, Rizzolatti G (1990) Cortico-cortical connections of two electrophysiologically identified arm representations in the mesial agranular frontal cortex. Exp Brain Res 82:214-218.

Luppino G, Matelli M, Camarda R, Rizzolatti G (1993) Corticocortical connections of area F3 (SMA-proper) and area F6 (pre-SMA) in the Macaque monkey. J Comp Neurol 338:114-140. 
Luppino G, Matelli M, Camarda R, Rizzolatti G (1994) Corticospinal projections from mesial frontal and cingulate areas in the monkey. NeuroReport 5:2545-2548.

Matelli M, Luppino G (1996) Thalamic input to mesial and superior area 6 in the Macaque monkey. J Comp Neurol 372:59-87.

Matelli M, Camarda R, Glickstein M, Rizzolatti G (1984) Interconnections within the postarcuate cortex (area 6) of the macaque monkey. Brain Res 310:387-392.

Matelli M, Luppino G, Rizzolatti G (1985) Patterns of cytochrome oxidase activity in the frontal agranular cortex of the macaque monkey. Behav Brain Res 18:125-136.

Matelli M, Camarda R, Glickstein M, Rizzolatti G (1986) Afferent and efferent projections of the inferior area 6 in the macaque monkey. J Comp Neurol 251:281-298.

Matelli M, Luppino G, Fogassi L, Rizzolatti G (1989) Thalamic input to inferior area 6 and area 4 in the macaque monkey. J Comp Neurol 280:468-488.

Matelli M, Luppino G, Rizzolatti G (1991) Architecture of superior and mesial area 6 and the adjacent cingulate cortex in the macaque monkey. J Comp Neurol 311:445-462.

Matsuzaka Y, Aizawa H, Tanji J (1992) A motor area rostral to the supplementary motor area (presupplementary motor area) in the monkey: neuronal activity during a learned motor task. J Neurophysiol 68:653-662.

Mink JW, Thach WT (1991) Basal ganglia motor control. III. Pallidal ablation: normal reaction time, muscle cocontraction, and slow movement. J Neurophysiol 65:330-351.

Miyachi S, Hikosaka O, Miyashita K, Karadi Z, Rand MK (1997) Differential roles of monkey striatum in learning of sequential hand movement. Exp Brain Res 115:1-5.

Morecraft RJ, Van Hoesen GW (1992) Cingulate input to the primary and supplementary motor cortices in the rhesus monkey: evidence for somatotopy in areas 24c and 23c. J Comp Neurol 322:471-489.

Morecraft RJ, VanHoesen GW (1993) Frontal granular cortex input to the cingulate (M3), supplementary (M2) and primary (M1) motor cortices in the Rhesus monkey. J Comp Neurol 337:669-689.

Muakkassa KF, Strick PL (1979) Frontal lobe inputs to primate motor cortex: evidence for four somatotopically organized "premotor" areas. Brain Res 177:176-182.

Mushiake H, Inase M, Tanji J (1991) Neuronal activity in the primate premotor, supplementary, and precentral motor cortex during visually guided and internally determined sequential movements. J Neurophysiol 66:705-718.

Nakamura K, Sakai K, Hikosaka O (1998) Neuronal activity in medial frontal cortex during learning of sequential procedures. J Neurophysiol 80:2671-2687.

Nakano K, Hasegawa Y, Tokushige A, Nakagawa S, Kayahara T, Mizuno N (1990) Topographical projections from the thalamus, subthalamic nucleus and pedunculopontine tegmental nucleus to the striatum in the Japanese monkey, Macaca fuscata. Brain Res 537:54-68.

Nakano K, Tokushige A, Kohno M, Hasegawa Y, Kayahara T, Sasaki K (1992) An autoradiographic study of cortical projections from motor thalamic nuclei in the macaque monkey. Neurosci Res 13:119-137.

Nambu A, Yoshida S, Jinnai K (1991) Movement-related activity of thalamic neurons with input from the globus pallidus and projection to the motor cortex in the monkey. Exp Brain Res 84:279-284.

Olszewski J (1952) The thalamus of the Macaca mulatta: an atlas for use with the stereotaxic instrument. Basel: Karger.

Parent A, DeBellefeuille L (1983) The pallidointralaminar and pallidonigral projections in primate as studied by retrograde double-labeling method. Brain Res 278:11-27.

Parent A, Hazrati LN (1995) Functional anatomy of the basal ganglia. I. The cortico-basal ganglia-thalamo-cortical loop. Brain Res Brain Res Rev 20:91-127.
Parent A, Mackey A, De Bellefeuille L (1983) The subcortical afferents to caudate nucleus and putamen in primate: a fluorescence retrograde double labeling study. Neuroscience 10:1137-1150.

Parthasarathy HB, Schall JD, Graybiel AM (1992) Distributed but convergent ordering of corticostriatal projections: analysis of the frontal eye field and the supplementary eye field in the macaque monkey. J Neurosci 12:4468-4488.

Percheron G (1977) The thalamic territory of cerebellar afferents and the lateral region of the thalamus of the macaque in stereotaxic ventricular coordinates. J Hirnforsch 18:375-400.

Rizzolatti G, Luppino G, Matelli M (1996) The classic supplementary motor area is formed by two independent areas. Adv Neurol 70:45-56.

Rouiller EM, Liang F, Babalian A, Moret V, Wiesendanger M (1994) Cerebellothalamocortical and pallidothalamocortical projections to the primary and supplementary motor cortical areas: a multiple tracing study in macaque monkeys. J Comp Neurol 345:185-213.

Sadikot AF, Parent A, Francois C (1992a) Efferent connections of the centromedian and parafascicular thalamic nuclei in the squirrel monkey: a PHA-L study of subcortical projections. J Comp Neurol 315:137-159.

Sadikot AF, Parent A, Smith Y, Bolam JP (1992b) Efferent connections of the centromedian and parafascicular thalamic nuclei in the squirrel monkey: a light and electron microscopic study of the thalamostriatal projection in relation to striatal heterogeneity. J Comp Neurol 320:228-242.

Sakai ST, Inase M, Tanji J (1996) Comparison of cerebellothalamic and pallidothalamic projections in the monkey (Macaca fuscata): a double anterograde labeling study. J Comp Neurol 368:215-228.

Schell GR, Strick PL (1984) The origin of thalamic inputs to the arcuate premotor and supplementary motor areas. J Neurosci 4:539-560.

Shima K, Tanji J (1998) Role for cingulate motor area cells in voluntary movement selection based on reward. Science 282:1335-1338.

Shima K, Aya K, Mushiake H, Inase M, Aizawa H, Tanji J (1991) Two movement-related foci in the primate cingulate cortex observed in signal-triggered and self-paced forelimb movements. J Neurophysiol 65:188-202.

Smith Y, Parent A (1986) Differential connections of the caudate nucleus and putamen in the squirrel monkey (Saimiri sciureus). Neuroscience 18:347-371.

Takada M, Tokuno H, Nambu A, Inase M (1998a) Corticostriatal input zones from the supplementary motor area overlap those from the contra- rather than ipsilateral primary motor cortex. Brain Res 791:335-340.

Takada M, Tokuno H, Nambu A, Inase M (1998b) Corticostriatal projections from the somatic motor areas of the frontal cortex in the macaque monkey: segregation versus overlap of input zones from the primary motor cortex, the supplementary motor area, and the premotor cortex. Exp Brain Res 120:114-128.

Tanji J, Shima K (1994) Role for supplementary motor area cells in planning several movements ahead. Nature 371:413-416.

Vogt BA, Pandya DN, Rosene DL (1987) Cingulate cortex of the Rhesus monkey: I. Cytoarchitecture and thalamic afferents. J Comp Neurol 262:256-270.

Wichmann T, DeLong MR (1996) Functional and pathophysiological models of the basal ganglia. Curr Opin Neurobiol 6:751-758.

Wiesendanger R, Wiesendanger M (1985) The thalamic connections with medial area 6 (supplementary motor cortex) in the monkey (macaca fascicularis). Exp Brain Res 59:91-104.

Wilson CJ, Chang JT, Kitai ST (1983) Origins of postsynaptic potentials in spiny neostriatal neurons by thalamic stimulation in the rat. Exp Brain Res 51:217-226.

Yeterian EH, Van Hoesen GW (1978) Cortico-striate projections in the rhesus monkey: the organization of certain cortico-caudate connections. Brain Res 139:43-63. 